conte ssops -3

CONF-880732--3

DE $90 \quad 001414$

LASER RAMAN SPECTROSCOPY IN STUDIES

OF CORROSION AND ELECTROCATALYSIS*

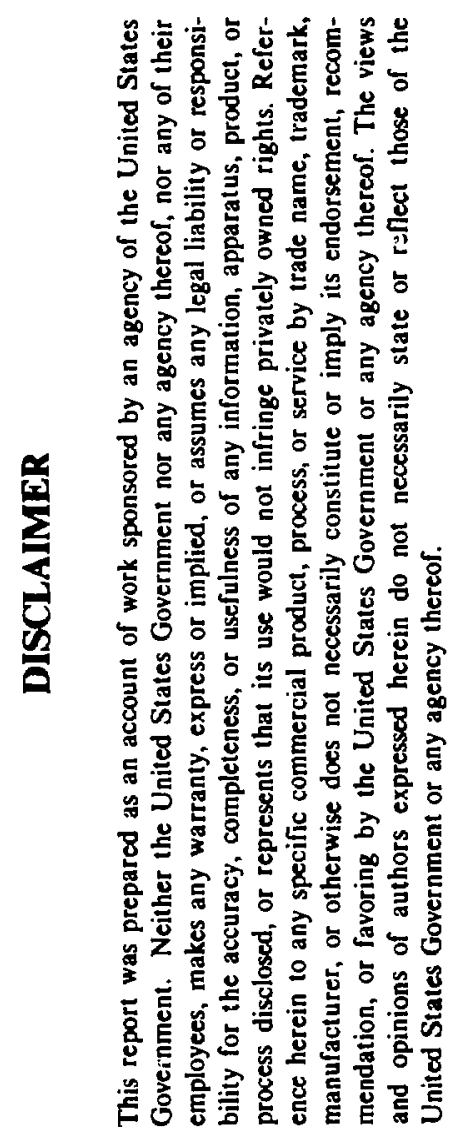

C. A. Melendres

Materials Science and Chemical Technology Divisions

Argonne National Laboratory

9700 South Cass Avenue

Argonne, Illinois 60439

U.S.A.

The submitted manuscript has bean suthored

by contractor of the U.S. Government

under contract No. W-3:-109ENG-38.

Accordingly, the U.S. Government retains a

According to publish

nonexclusive, rovalivelrese license form of this

or reproduce the publined torm of this

contribution, or allow others to do $\%$, for
U. S. Government purposes.

*Work supported by the U.S. Department of Energy, Office of Basic Energy Sciences, Division of Materials Science, under contract W-31-109-Eng-38. 


\title{
LASER RAMAN SPECTROSCOPY IN STUDIES OF CORROSION AND ELECTROCATALYSIS
}

\author{
C. A. Melendres \\ Materials Science and Chemical Technology Divisions \\ Argonne National Laboratory \\ Argonne, Illinois 60439 \\ U.S.A.
}

ABSTRACT. Laser Raman Spectroscopy (LRS) has become an important tool for the in-situ structural study of electrochemical systems and processes in recent years. Following a brief introduction of the experimental techniques involved in applying LRS to electrochemical systems, we survey the literature for examples of studies in the inhibition of electrode reactions by surface films (e.g., corrosion and passivation phenomena) as well as the acceleration of reactions by electro-sorbates (electrocatalysis). We deal mostly with both normal and resonance Raman effects on fairly thick surface films in contrast to surfaceenhanced Raman investigations of monolayer adsorbates, which is covered in another lecture.

Laser Raman spectroelectrochemical studies of corrosion and filn formation on such metals as $\mathrm{Pb}, \mathrm{Ag}, \mathrm{Fe}, \mathrm{Ni}$, Co, $\mathrm{Cr}$, Au, stainless steel, etc. in various solution conditions are discussed. Further extension of the technique to studies in high-temperature and highpressure aqueous environments is demonstrated. Results of studies of the structure of corrosion inhibitors are also presented.

As applications of the LRS technique in the area of electrocatalysis, we cite studies of the structure of transition metal macrocyclic compounds, i.e., phthalocyanines and porphyrins, used for catalysis of the oxygen reduction reaction.

\section{INTRODUCTION}

Laser Raman Spectroscopy (LRS) has become an important tool for the study of electrochemical systems and processes because of the molecular specific information that it provides on the structure of the solid/ solution interface in situ.1,2a,b The spectrum of the inelastically scattered light from a sample contains information related to the various normal modes of vibration of the system and constitutes a fingerprint by which the material can be identified. Such specific structural information nicely supplements the kinetic data contained in the conventional current-potential curve and is essential for arriving at a 
detailed interpretation of the mechanism of electron-transfer reactions. The technique also nicely complements vibrational information obtained by infrared spectroscopy. Numerous applications of LRS to electrochemistry have been made since Fleischmann and Hendra $2 a$ first reported use of the technique to study the composition of solid phases electrochemically formed on mercury. The study of anodically-formed surface phases and corrosion films continues to be an important application of the technique; work in this area since 1973 is surveyed here. We also cite applications of LRS to investigations of electrocatalysis. Techniques and instrumentation in Raman spectroscopy are well covered in another lecture; only a few important points are discussed here. We deal mostly with practical applications in order to illustrate the power of the technique. We also digress on the limitations and problems in its use to study interfacial electrochemical phenomena. Examples are taken from the literature and from the author's own work. The illustrations are not meant to be all inclusive, rather just of sufficient detail to be helpful to the beginner in the field.

\section{THEORETICAL AND EXPERIMENTAL ASPECTS}

When light of a single frequency $\nu_{0}$ strikes a sample (Fig. 1a), the scattered radiation is found to consist of a number of discrete frequencies which can be grouped into three categories, i.e. $\nu_{0}-\nu_{v i b}$, $\nu_{0}$, and $\nu_{0}+\nu_{v i b}$, where $\nu_{v i b}$ is the frequency of a normal vibration 1,18 of the material. Raman spectroscopy consists in the measurement and analysis of the inelastically scattered light of frequency $\nu_{0}$ - $\nu_{\mathrm{vib}}, \nu_{\mathrm{o}}+\nu_{\mathrm{vib}}$, etc. The set of spectral lines of lower frequency than $\nu_{0}$, i.e., $\nu_{0}-\nu_{v i b}$, are called the Stokes lines, while those with higher frequencies, $\nu_{\mathrm{o}}+\nu_{\mathrm{vib}}$ are referred to as anti-stokes lines. The elastically scattered light of frequency $\nu_{0}$ is termed the Raleigh line. The change in energy states that accompany the scattering process is schematically illustrated in Fig. 1b, where a molecule is excited from the electronic state (with vibrational levels $v=0,1$ ) to a virtual higher electronic state. The corresponding Raman spectrum is shown schematically in Fig. 1c. From an analysis of such Raman spectra, it is possible to extract molecular electronic structural information from a calculation of the set of fundamental vibrational frequencies, $\nu_{\text {vib. }}$

The intensity of the scattered Raman light has been derived and shown to be $1 \mathrm{~b}$

$$
I_{\text {scat }}=k\left(\nu_{0}-\nu_{v i b}\right)^{4}\left(\mathrm{~d} a_{z z} / d r\right)^{2} I_{0}
$$

where $I_{0}$ is the incident light intensity, $\left(\mathrm{d} a_{z z} / \mathrm{dr}\right)$ is the change of molecular polarizability $a_{z z}$ with vibrational coordinate $r$, and $k$ is a constant. It is important to note the dependence of the intensity on the fourth power of the frequency of the scattered light. Likewise, the essential requirement (selection rule) for observation of the Raman effect is that the polarizability of the molecule change with vibration, i.e., da/dr $\neq 0$. 

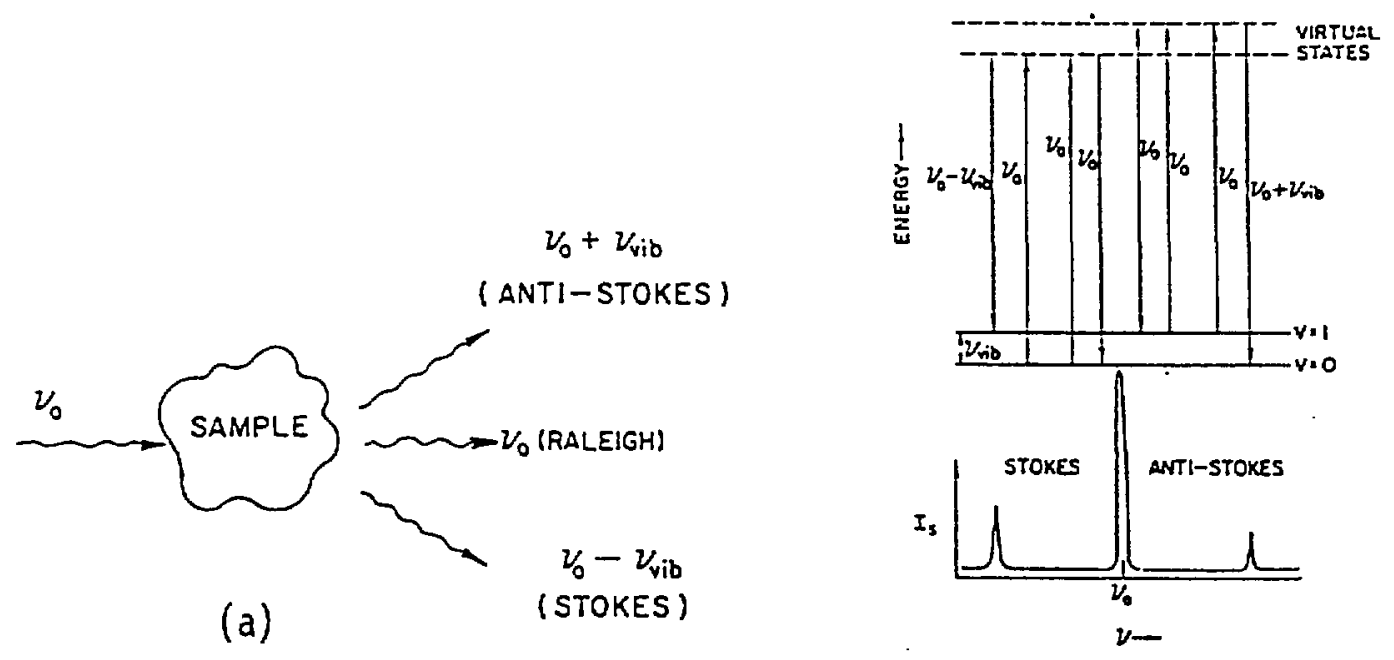

(b)

Figure 1. (a) Light scattering from a material; (b) Schematic energy level diagram illustrating transitions that give rise to Raman spectra; (c) Sample spectrum corresponding to (b).

The instrumentation required for LRS consists simply of a light source for exciting the sample, an analyzer to determine the wavelengths of the scattered light, and a detector to measure the intensity of the scattered radiation. The sample is contained in an electrochemical cell of suitable design. Commonly used source of high intensity and coherent light are lasers, e.g., $\mathrm{Ar}^{+}$or $\mathrm{Kr}^{+}$gas lasers, which provide discrete wavelengths in the visible region from about 450 to 680 $\mathrm{nm}$. Dye lasers provide tunability over a wider range of wavelengths. Analysis of the frequency distribution of the scattered light is done with single-, double-, or triple-stage monochromators, which are outfitted with appropriate gratings and mirrors for dispersion of the incoming collected light beam. Choice of monochromators is often made in conjunction with the detector used. The latter can be a photomultiplier tube for single-channel photon counting or maybe one of a number of multichannel optical detectors, such as a diode array, silicon intensified target, or a silicon photon imaging detector. Further details on this subject are given in the paper by Chang in this proceedings volume. The ultimate aim of instrument design is to maximize the detection of the inelastically scattered light. The magnitude of this problem may be appreciated by realizing that this fraction is only about $10^{-6}$ that of the incjent light intensity, $I_{0}$. The scattered light intensity, Iscat from molecules on an electrode surface is given by,

$$
I_{\text {scat }}=2 I_{0} \times N \times(\partial \sigma / \partial \Omega)
$$

where $\mathrm{N}$ is the number density of molecules on the surface per $\mathrm{cm}^{2}$ and $\partial \sigma / \partial n$ is the differential cross section of the molecule for Raman scattering, usually in the range of $10^{-31} \mathrm{~cm}^{2} /$ steradian. The amount of 
light detected by a spectrometer system is

$$
I_{\text {det }}=I_{\text {scat }} \times 1 \times t \times(\Omega / 4 \Pi) \times R
$$

where 1 is the path length of the beam on the sample, t the time for data collection, $\mathbf{\Omega}$ the solid angle subtended by the detector and $\mathrm{K}$ the instrument response. The latter is the amount of light detected divided by the amount entering the spectrometer. From equations (2) and (3), it follows that the detected light intensity is

$$
I_{\text {det }}=k, \times N \times t \times R \times(\partial \sigma / \partial \Omega)
$$

where the proportionality constants have been lumped into a single one, $\mathrm{k}^{\prime}$. Equation (4) shows how the Raman signal may be increased by increasing the density of molecules on the surface, the time for data accumulation, and the instrument response, $R$. The scattering cross section may be increased by making use of the resonance Raman effect. ${ }^{1 b}$ Veirs $2 \mathrm{C}$ has compared the instrument response for a double monochromator fitted with a photomultiplier tube detector, a triple spectrometer equipped with an intensified photo-diode array, and a single monochromator with an imaging photomultiplier tube. He found $R$ for these systems to be in the ratio of $1: 13: 300$.

An experimental setup employed in the author's laboratory for in situ LRS of electrochemical systems is shown in Fig. 2. The threecompartment spectroelectrochemical cell $^{3}$ is fitted with a special highpuricy quartz window inclined at an angle of $60^{\circ}$ with respect to the horizontal. This is nearly the optimum angle for maximum scattering intensity for most metals as shown by Campion. ${ }^{2 b}$ The working electrode is brought to within $0.5 \mathrm{~mm}$ of this window to minimize the solution volume being traversed by the laser beam striking the electrode surface. The scattered radiation is collected at an angle of $90^{\circ}$ with respect to the incident beam direction and then analyzed in the double monochromator. The light intensity is measured by a photomultiplier tube detector together with associated photon-counting electronics.

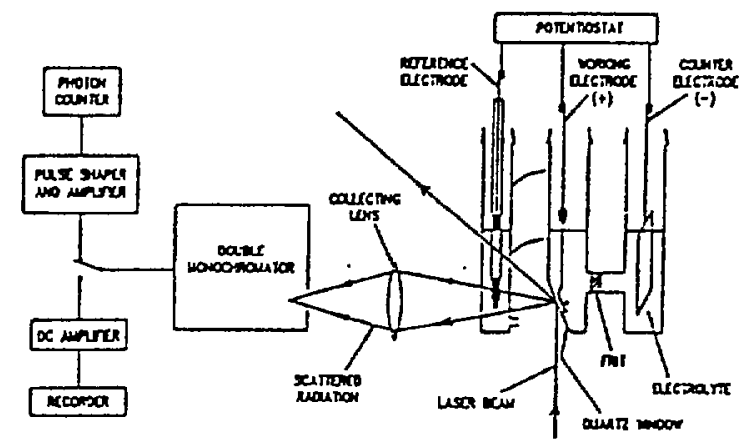

Figure 2. Experimental set-up for laser Raman spectroelectrochemical studies. 
of important consideration in the LRS experiments are the laser frequency for exciting the sample and the incident beam power. The latter is so chosen to be sufficiently intense to obtain a reasonably good signal without causing composition or structural changes in the sample. For a laser beam of $2 \mathrm{~mm}$ diameter incident on a sample, a power level of 50 to $150 \mathrm{~mW}$ is often adequate. The choice of excitation frequency is usually dictated by the laser sources available. Commonly used sources are $\mathrm{Ar}^{+}$and $\mathrm{Kr}^{+}$lasers with a number of usable wavelengths in the visible spectral range from about $460 \mathrm{~nm}$ to $650 \mathrm{~nm}$. It is sometimes of great advantage to select a laser exciting frequency to be coincidental with the electronic absorption spectrum of the material, thus allowing for signal enhancement via the resonance Raman effect.

\subsection{Studies of Corrosion and Passivation Films on Metals}

The determination of the structure and composition of corrosion films on metals constitutes one of the most important practical application of laser Raman spectroelectrochemistry. An understanding of the relationships between composition and physico-electrochemical properties of passive films is essential to the technological development of methods for controlling the degradation of materials via corrosive mechanisms. Over a dozen metals have been studied by LRS under a variety of solution environments. Among these are $\mathrm{Ag}, 3 \mathrm{Au},{ }^{4} \mathrm{~Pb}, 5,6 \mathrm{Hg},{ }^{2} \mathrm{Cu}, 7,8 \mathrm{Co}, 9$ $\mathrm{Fe}, 10-12 \mathrm{Ni}, 13$ and $\mathrm{Fe}-\mathrm{Cr}$ alloys. 37 We review here results of studies on these systems and in the process illustrate the kind of information obtainable by the Raman technique.

\subsection{Lead and Mercury}

The corrosion films on lead and mercury metals were among the first to be studied by LRS for good reasons. High atomic number elements combine to form large molecules with highly polarizable electronic structures and hence have relatively large cross sections for Raman scattering. Raman spectral intensities are, therefore, high and detection sensitivities are better than for molecules composed of lower atomic number elements.

Fleischman and his group 2 a first studied the formation of solid phases on a $\mathrm{Hg}$ surface by LRS. By constant potential anodization in $\mathrm{HCl}$ and $\mathrm{HBr}$ solutions, they produced the surface phases $\mathrm{Hg}_{2} \mathrm{Cl}_{2}$ and $\mathrm{Hg}_{2} \mathrm{Br}_{2}$ respectively, which yielded characteristic Raman bands at 41 , 168 , and $273 \mathrm{~cm}^{-1}$ for the chloride and 36,135 , and $218 \mathrm{~cm}^{-1}$ for the bromide. HgO was prepared from $\mathrm{NaOH}$ solution and showed bands at 330 and $567 \mathrm{~cm}^{-1}$.

Corrosion and $\mathrm{film}$ formation on $\mathrm{Pb}$ have been studied in aqueous chloride $5 b$ and sulfate $5 a, 6$ solutions. Reid, Cooney, et al. $5 b$ investigated $\mathrm{Pb}$ in chloride media in order to verify the phases predicted by the Pourbaix diagram. They suspected the existence of the polymeric phase $[\mathrm{Pb}(\mathrm{OH})]_{n} \cdot \mathrm{Cl}_{n}$ which did not appear in the diagram. They studied films formed at different $\mathrm{pH}^{\prime} \mathrm{s}$ as a function of applied potential in order to confirm their theory; they then proposed the inclusion of the 
phase $[\mathrm{Pb}(\mathrm{OH})]_{n} \cdot \mathrm{Cl}_{n}$ in the construction of the Pourbaix diagram of the $\mathrm{Pb} / \mathrm{H}_{2} \mathrm{O}$ system. Investigations with a similar objective were undertaken by Thibeau et al. $5 a, 15$ who found that the composition of surface films on $\mathrm{Pb}$, which was corroded in $0.1 \mathrm{M}$ sulfate, were not in complete agreement with the predictions of the calculated potential-pH diagram. The Pourbaix diagram ${ }^{17}$ did not predict the formation of $\mathrm{PbO}$ under any condition; however, they obtained spectra of this phase at various potentials in acid and neutral solutions and at potentials above the immunity region in basic solutions. Pourbaix diagrams of $\mathrm{Pb}$ in the presence of $\mathrm{SO}_{4}=$ have been constructed by Thibeau et al. ${ }^{15}$ and McMahon et al. ${ }^{16}$ for sulfate activities of 0.1 and $6.4 \times 10^{-4}$, respectively. The latter construction is presented in Fig. 3. As can be seen, both sulfate and

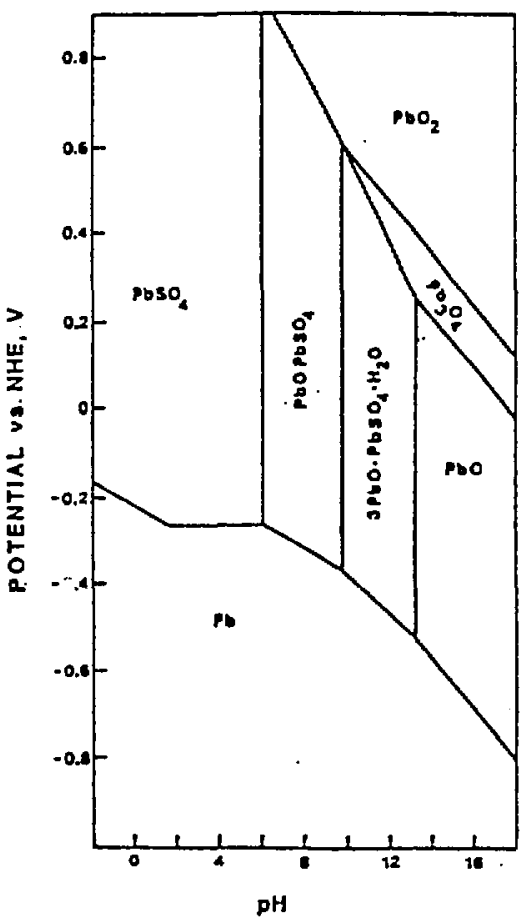

Figure 3. Pourbaix diagram of the $\mathrm{Pb}-\mathrm{OH}_{2} \mathrm{O}$ system at $25^{\circ} \mathrm{C}$ for a sulfate activity of $6.4 \times 10^{-4}$ (from reference 16 ).

oxide surface phases are predicted to exist depending on the electrode potential and solution $\mathrm{pH}$. We studied the corrosion of $\mathrm{Pb}$ in $0.05 \mathrm{M}$ $\mathrm{H}_{2} \mathrm{SO}_{4}$ solution ( $\mathrm{pH}=1.6$ ) initially; ${ }^{6}$ a cyclic voltammogram is shown in Fig. 4a. Typical active dissolution and passivation behavior is observed with the various regions indicated in the figure. The Pourbaix diagram predicts that controlled potential anodization at 0.16 $\mathrm{V}$ vs SHE $\left(-0.45 \mathrm{~V}\right.$ vs $\left.\mathrm{Hg} / \mathrm{Hg}_{2} \mathrm{SO}_{4}\right)$ should lead to the formation of $\mathrm{PbSO}_{4}$ on the surface. The Raman spectrum observed in-situ (Fig. 4b) shows the most intense bands of $\mathrm{PbSO}_{4}$. Assignment of these bands was done by a comparison with the spectrum of a standard sample known to be $\mathrm{PbSO}_{4}$ (Fig. 4C). Confirmation of this assignment was carried out by $\mathrm{X}$-ray 

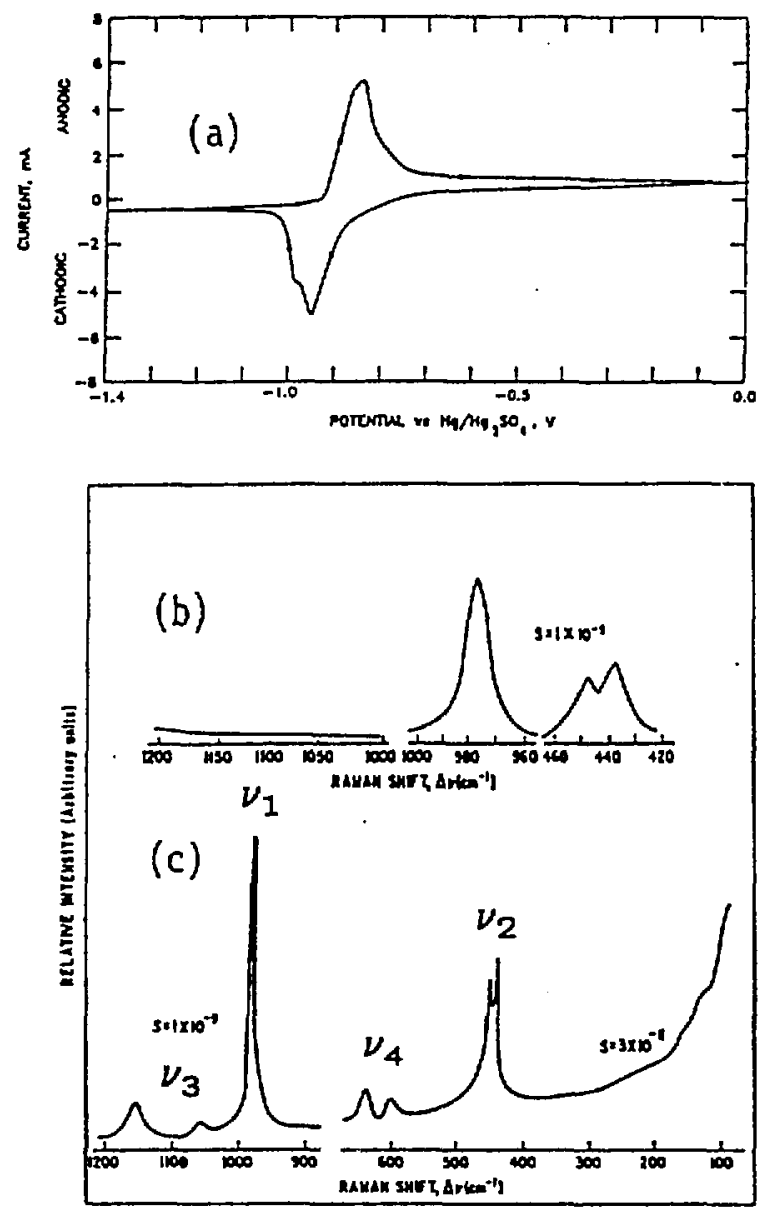

Figure 4. (a) Cyclic voltammogram of $\mathrm{Pb}$ in $0.05 \mathrm{M} \mathrm{H}_{2} \mathrm{SO}_{4}$ at $25^{\circ} \mathrm{C}$ (scan rate $=10 \mathrm{mV} / \mathrm{sec}$ ); (b) In-situ Raman spectrum of anodic corrosion film on $\mathrm{Pb}$ at $0.16 \mathrm{~V}$ vs SHE; (c) Raman spectrum of standard $\mathrm{PbSO}_{4} \mathrm{Ar}^{+}$laser, $488 \mathrm{~nm}$ line, Power $\simeq 280 \mathrm{~mW}, \mathrm{~s}=$ sensitivity scale.

diffractions analysis of the surface film. Moreover, from a theoretical analysis of the number and groups of vibrational frequencies observed, one can also surmise that the three bands observed correspond to two of the four modes of vibration of the $\mathrm{SO}_{4}=$ group that belong to different symmetry classifications ${ }^{18}$. The $\mathrm{SO}_{4}=$ anion is tetrahedral with $\mathrm{T}_{\mathrm{d}}$ symmetry. Theory predicts the appearance of four groups of bands in the Raman spectrum of $\mathrm{SO}_{4}=$ compounds. From Fig. $4 \mathrm{C}$ it is evident that four such groups of bands are indeed observed. The splitting of the degenerate bands $\nu_{2}, \nu_{3}$, and $\nu_{4}$ is apparent and is brought about by the internal electric fields in the crystal that the ion experiences.

Further anodic oxidation of the lead electrode at a higher potential should produce a new phase, e.g., $\beta-\mathrm{PbO}_{2}$ in acid solutions. 20 on stepping the potential from 0.16 to $1.95 \mathrm{~V}$ vs SHE in $0.05 \mathrm{M} \mathrm{H}_{2} \mathrm{SO}_{4}$ in our experiment, we observed the white $\mathrm{PbSO}_{4}$ layer to convert to a black 
coating which was identified by XRD as $\beta-\mathrm{PbO}_{2}$. However, the Raman spectrum we observed was irreproducible and depended on the laser power incident on the sample. There seemed to be an induction time of a few minutes following laser irradiation before a spectrum could be observed. Similar observations were made on a standard $\beta-\mathrm{PbO}_{2}$ sample. Rotation of the sample caused some of the peaks to disappear or to shift in frequency. On removal of the sample from the spectrometer, we found peach colored spots where the laser beam had impinged on the sample. It is evident that the laser beam had been changing the sample at the point of impact, causing some transformation of the $\beta-\mathrm{PbO}_{2}$ to other forms of $\mathrm{Pb}$ compounds and leading to erroneous results. This is a good illustration of a problem associated with the study of dark and strongly light absorbing samples by the Raman technique. Sample heating by the laser beam can lead to changes in chemical composition or phase transformation of strongly light absorbing materials. It is, therefore, necessary to employ as low a laser power as possible consistent with obtaining a reasonable Raman signal. It is also important to check that no composition or phase change is occurring by obtaining spectra at different laser power levels.

\subsection{Silver and Gold}

Silver and gold have figured prominently in surface enhanced Raman spectroscopy (SERS) investigations where they are used as substrates for structural studies of absorbed molecules as well as for investigations onto the mechanism of surface enhancement. Kötz et al., ${ }^{3}$ as well as Hamilton and co-workers, ${ }^{8}$ investigated $\mathrm{Ag}$ in alkaline solutions while work in our laboratory was carried out in acid sulfate solutions. ${ }^{7}$ In $\mathrm{NaOH}$, the cyclic voltammogram of $\mathrm{Ag}$ exhibits two anodic waves at about 0.4 and $0.6 \mathrm{~V}$ vs $\mathrm{Hg} / \mathrm{HgO}$ corresponding to the formation of surface layers of $\mathrm{Ag}_{2} \mathrm{O}$ and $\mathrm{AgO}$, respectively. ${ }^{3}$ AgO was identified by a strong band at $430 \mathrm{~cm}^{-1}$ at a sensitivity of about 10 monolayers. on the other hand, $\mathrm{Ag}_{2} \mathrm{O}$ could not be detected because of laser photodecomposition which led to the formation of $\mathrm{AgO}^{3}$

In $0.05 \mathrm{M} \mathrm{H}_{2} \mathrm{SO}_{4}$ solution, ${ }^{7}$ anodic oxidation occurs at about $0.3 \mathrm{~V}$ vs $\mathrm{Hg} / \mathrm{Hg}_{2} \mathrm{SO}_{4}$ resulting in the formation of $\mathrm{a} \mathrm{Ag}_{2} \mathrm{SO}_{4}$ film on the electrode surface (Fig. 5). Raman spectra as a function of potential are shown in Fig. 6; the bands at 450,608,960 and $1130 \mathrm{~cm}^{-1}$ are again characteristic of $\mathrm{SO}_{4}=$, while the low frequency band at $\sim 229 \mathrm{~cm}^{-1}$ is probably due to vibration of the whole $\mathrm{SO}_{4}=$ group with respect to the $\mathrm{Ag}$ surface or to $\mathrm{Ag}^{+}$adatoms on the surface. Conversion of the $\mathrm{Ag}_{2} \mathrm{SO}_{4}$ film to $\mathrm{Ag}_{7} \mathrm{O}_{8} \mathrm{SO}_{3}$ (which is a $\mathrm{AgO}$ phase containing some $\mathrm{SO}_{4}=$ impurity) has been observed by X-ray diffraction analysis (XRD) following anodization at about $1.3 \mathrm{~V}$.

Gao et al. 22 studied gold extensively as an ubiquitous substrate for obtaining intense SERS. They prescribed a series of oxidationreduction cycles at well defined potential limits in $0.1 \mathrm{M} \mathrm{KCl}$ that can be used to generate optimum surface conditions for obtaining strong signals. Gold is, moreover, interesting because of the relatively wide electrochemical "window" available for investigating electron transfer 


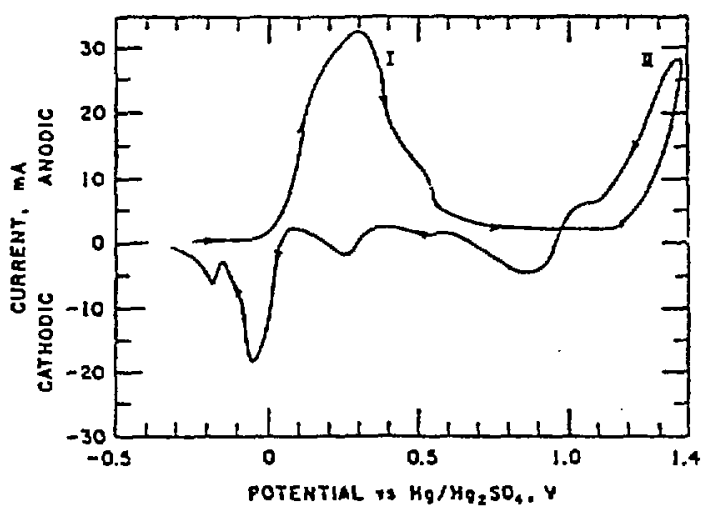

Figure 5. Cyclic voltammogram of $\mathrm{Ag}$ in $0.05 \mathrm{M} \mathrm{H}_{2} \mathrm{SO}_{4}$ at $25^{\circ} \mathrm{C}$. Scan rate $=5 \mathrm{mV} / \mathrm{sec}$, Electrode area $=0.9 \mathrm{~cm}^{2}$.

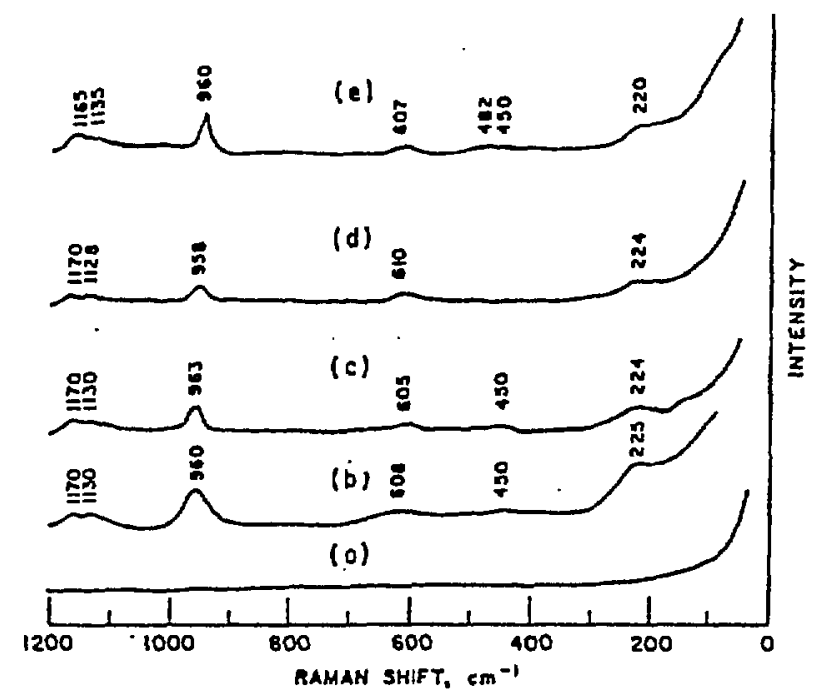

Figure 6. In-situ Raman spectra of $\mathrm{Ag}$ anodized at various potentials in $0.05 \mathrm{M} \mathrm{H}_{2} \mathrm{SO}_{4}$; (a) Open circuit $\left(\mathrm{OCV}\right.$ ) $=-0.02 \mathrm{~V}$ vs $\mathrm{Hg} / \mathrm{Hg}_{2} \mathrm{SO}_{4}$, (b) $0.18 \mathrm{~V}$, (c) $0.55 \mathrm{~V}$, (d) $0.75 \mathrm{~V}$, (e) $1.30 \mathrm{~V}$; $\mathrm{Ar}^{+}$laser, $514.5 \mathrm{~nm}$ line, Power $=80 \mathrm{~mW}$.

reactions. The surface is nonetheless oxidized at fairly anodic potentials, and the structural changes have been studied by DeSilvestro and Weaver. ${ }^{23}$ The latter work exploited the power of SERS to obtain information on the initial stages of film formation and growth in aqueous solutions. The authors found that during the anodic oxidation of $\mathrm{Au}$ in $1 \mathrm{M} \mathrm{KOH}$, two Raman bands are observed; one $\left(\nu_{1}\right)$ occurs at around 400-430 $\mathrm{cm}^{-1}$ which appears at about $-0.25 \mathrm{~V}$ vs SCE, and another band $\nu_{2}$ from 0.2 to $0.25 \mathrm{~V}$ (the so-called "pre-oxide" formation region of the current-potential, i-E, curve). Applying a more positive potential ( $\sim 0.2$ to $0.25 \mathrm{~V}$ ) curresponding to the beginning of the voltammetric "anodic oxide" region resulted in the disappearance of $\nu_{1}$ 
and the appearance of a new band, $\nu_{2}$, at $\sim 540 \mathrm{~cm}^{-1}$. These bands were assigned to Au-OH vibrations based on their frequency shifts in similar experiments carried out using deuterated water as solvent. The model of anodic surface oxidation of noble metals has been propcsed 24 to consist of two steps: 1) initial adsorption of $\mathrm{O}$ or OH, followed by 2) place exchange with the surface metal atoms along with further electron transfer to form the "oxide film." Desilvestro and Weaver assigned the $\nu_{1}$ band to reversibly adsorbed $\mathrm{OH}^{-}$in step 1 and $\nu_{2}$ to the "oxide film" formed in step 2. The $\nu_{2}$ frequency of 540 to $580 \mathrm{~cm}^{-1}$ however: appears to be lower than that due to surface $\mathrm{Au}_{2} \mathrm{O}_{3}\left(\sim 650 \mathrm{~cm}^{-1}\right)$ as observed by Electron Energy Loss Spectroscopy (EELS) and for bulk $\mathrm{Au}(\mathrm{OH})_{3}$ as obtained by Raman spectroscopy $\left(\sim 635 \mathrm{~cm}^{-1}\right)$. The charge associated with the oxide film appears to be equivalent to or even less than one monolayer.

\subsection{Copper and Cobalt}

Copper too exhibits the SER effect; it is also of great interest industrially as a material for heat exchanger tubes and its corrosion behavior has been characterized electrochemically in a wide variety of aqueous solution environments. Raman spectroscopic studies had been carried out by Hamilton et al. ${ }^{8}$ in alkaline solution; we have undertaken investigations in sulfate. ${ }^{7}$ The voltamnogram of $\mathrm{Cu}$ in $0.1 \mathrm{M}$ $\mathrm{NaOH}$ shows anodic waves at about $-0.40 \mathrm{~V}$ and $0.0 \mathrm{~V}$ vs SCE with corresponding cathodic reduction waves at about -0.7 and $-0.8 \mathrm{~V}$, respectively. Using an optical multichannel detector, Hamilton et al. monitored the initial formation of $\mathrm{Cu}_{2} \mathrm{O}$ at $649 \mathrm{~cm}^{-1}$ near $0.05 \mathrm{~V}$ with $\mathrm{Ar}^{+}$laser excitation using the $488 \mathrm{~nm}$ line. For potentials more anodic than about $600 \mathrm{mV}$ a broad band appeared between 500 and $650 \mathrm{~cm}^{-1}$. This band was assigned to $\mathrm{Cu}(\mathrm{OH})_{2}$. The formation of $\mathrm{Cu}_{2} \mathrm{O}$ at $-367 \mathrm{mV}$ was visible in the spectra after passing $6.8 \mathrm{mc} / \mathrm{cm}^{2}$ of chagge leading the authors to conclude that they could detect a film $\sim 40 \mathrm{~A}$ thick. They also found the Raman scattering intensity to be proportional to the film thickness. The authors did not observe scattering from the $\mathrm{Cu}_{2} \mathrm{O}$ film using laser excitation with the $647.1 \mathrm{~nm}$ line. Since $\mathrm{Cu}_{2}{ }^{\mathrm{O}}$ has an optical absorption edge close to the $488 \mathrm{~nm}$ line of the $\mathrm{Ar}^{+}$laser being used they concluded that the detection of the $\mathrm{Cu}_{2} \mathrm{O}$ was by resonance Raman scattering.

The cyclic voltammogram of $\mathrm{Cu}$ in $1 \mathrm{M} \mathrm{Na}_{2} \mathrm{SO}_{4}$ is shown in Fig. $7 \mathrm{a}$; $\mathrm{Cu}$ does not completely passivate in sulfate solution. 7 Film formation occurs, however, and the spectrum in situ at $0.2 \mathrm{~V}$ is shown in Fig. $7 \mathrm{~b}$. The bands at 145,214 , and $644 \mathrm{~cm}^{-1}$ for the red-orange film formed are assigned to $\mathrm{Cu}_{2} \mathrm{O}$, the presence of which is confirmed by XRD analysis. Interestingly, a $\mathrm{Cu}_{2} \mathrm{SO}_{4} \mathrm{film}$ was not observed, this compound being rather soluble in the solution.

We have also examined the composition of surface films on Co in $0.05 \mathrm{M} \mathrm{NaOH}$ solution. 9 Previous spectroscopic investigations have consisted mainly of ellipsometry 25,26 and Mossbauer spectroscopy. 27,28 At $\mathrm{pH} 11.9$ in $0.05 \mathrm{M} \mathrm{NaOH}$, the Pourbaix diagram of the Co- $\mathrm{H}_{2} \mathrm{O}$ system predicts the formation of the phases $\mathrm{Co}(\mathrm{OH})_{2}, \mathrm{Co}_{3} \mathrm{O}_{4}, \mathrm{Co}(\mathrm{OH})_{3}$, and $\mathrm{CuO}_{2}$ with increasing potential. 17 The current-potential curve shows an 

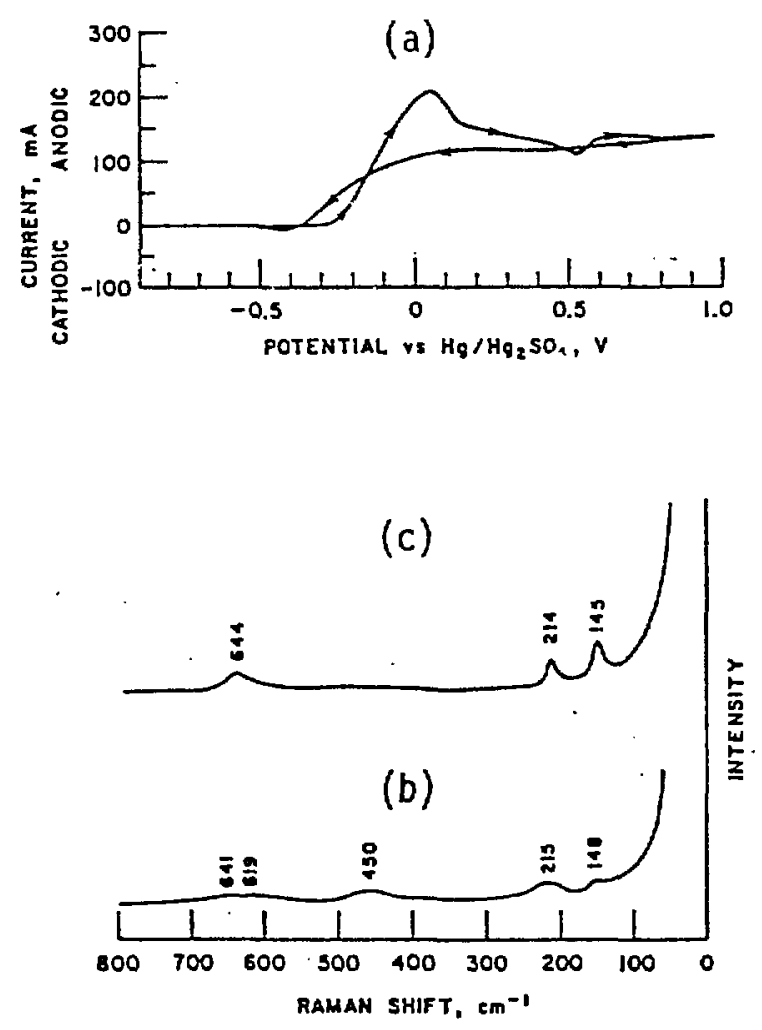

Figure 7. (a) Cyclic voltammogram of $\mathrm{Cu}$ in $1 \mathrm{M} \mathrm{Na}_{2} \mathrm{SO}_{4}$, Scan rate $=5$ $\mathrm{mV} / \mathrm{sec}$, Electrode area $=1.3 \mathrm{~cm}^{2}$; (b) In-situ Raman spectrum of anodic corrosion film on $\mathrm{Cu}$ at $0.2 \mathrm{~V}$; (c) Ex-situ spectrum, $\mathrm{Ar}^{+}$laser, $488 \mathrm{~nm}$ line, Power $=40-100 \mathrm{~mW}$.

anodic wave at about $-0.5 \mathrm{~V}$ vs $\mathrm{Hg} / \mathrm{HgO}$ assigned to the formation of CoO and two other waves between 0 and $0.5 \mathrm{~V}$ which had been assigned by Sato et al. 25,26 to the formation of $\mathrm{Co}(\mathrm{OH})_{3}$ and $\mathrm{Co}_{3} \mathrm{O}_{4}$. Our laser Raman investigation of this system did not yield any spectrum in the primary passive region at about $-0.2 \mathrm{~V}$ but showed a multiplet of bands in the secondary passive region at $\sim 0.45 \mathrm{~V}$. In-situ measurements showed weak bands at $475,515,587$, and $690 \mathrm{~cm}^{-1}$. Comparison of these lines with the spectra of standard samples of $\mathrm{CoO}, \mathrm{CO}_{3} \mathrm{O}_{4}$ and $\mathrm{Co}(\mathrm{OH})_{2}$ led us to conclude that the secondary passive film consists of a mixture of CoO and $\mathrm{Co}_{3} \mathrm{O}_{4}$. This is in agreement with sato's finding that a bilayer film of $\mathrm{CoO} / \mathrm{Co}_{3} \mathrm{O}_{4}$ oxide exists at the $\mathrm{Co}$ surface in the potential range that we have studied.

\subsection{Titanium}

Ohtsuka, Guo and sato 48 studied the anodic oxide films on titanium at various potentials both in neutral phosphate and acidic sulfate solutions. Following anodic oxidation for one hour to form the film at constant potentials of 5.6 and $10.6 \mathrm{~V}$ vs RHE in neutral phosphate solution $(0.1 \mathrm{M}, \mathrm{pH} 6.9)$, the electrodes were examined in-situ at $1.60 \mathrm{~V}$ to 
avoid oxygen evolution. Raman bands at $145,400,515$ and $640 \mathrm{~cm}^{-1}$ were observed which were identified with the anatase form of $\mathrm{TiO}_{2}$. Similar bands were observed in $0.1 \mathrm{M} \mathrm{H}_{2} \mathrm{SO}_{4}$ solution after anodizing for one hour at 8.1 and $10.1 \mathrm{~V}$ then holding at $1.6 \mathrm{~V}$ vs RHE. They were unable to observe Raman bands below $4 \mathrm{~V}$ although the film thickness measured about $13 \mathrm{~nm}$. They hypothesized that the film is still amorphous at this potential but transforms into a more crystalline structure at higher potentials. Thus they begin to see Raman bands at $5.6 \mathrm{~V}$ where they also observed the electrode surface to have a crater-like morphology. Strong bands due to the anatase modification were observed at 10 $V$ where the oxide film appears to have a ripple-Iike morphology.

Hugot Le-Goff also reported work on thin $\mathrm{TiO}_{2}$ films by interference enhanced Raman spectroscopy. $38 \mathrm{a}, \mathrm{b}$ she found that films grown by anodic oxidation of $\mathrm{Ti}$ consist of two different crystallographic forms that depended on the formation potential. Films prepared at potentials higher than $50 \mathrm{~V}$ were composed of anatase while those formed at lower potentials were microcrystalline, consisting of aggregates of 20 to 25 atoms each having the local order of anatase. The spectra of these two types were different; the anatase spectrum showed bands at 398,520 and $625 \mathrm{~cm}^{-1}$, while the microcrystals showed bands at 350 and $630 \mathrm{~cm}^{-1}$. The author found that an electropolished $\mathrm{Ti}$ sample left in air for a long period of time developed a film whose spectrum was the same as the thin microcrystalline film. The author took advantage of enhancement of the Raman signal by interference effects in the film which varied as a function of thickness; a 10 to 20 times enhancement was obtained.

More recently Felske and Plieth ${ }^{38 \mathrm{C}}$ obtained in-sicu Raman spectra of oxide films electrochemically formed on $\mathrm{Ti}$ in $0.5 \mathrm{M} \mathrm{H}_{2} \mathrm{SO}_{4}$. They observed that below the formation potential of $10 \mathrm{~V}$, the spectra were clearly due to rutile; at higher potentials, however, the spectra were neither characteristic of rutile nor anatase. Upon electrode emersion and drying of the film, spectra due to anatase were evident. An identical spectrum was obtained when the oxide film was formed in $\mathrm{HNO}_{3}$. In all cases, the films appeared to be crystalline. The authors felt that differences in their results with those of others may be due to the film formation and ageing conditions.

\subsection{Nickel and Iron}

Nickel and iron have been most extensively studied electrochemically for their corrosion characteristics because of their industrial importance. Their electrochemical reactivities are also of great interest for the operation of $\mathrm{Ni}-\mathrm{Fe}$ and other batteries. We studied the anodic corrosion of $\mathrm{Ni}$ in alkaline and near-neutral solutions ${ }^{9}$ while

Delichere, Hugot Le-Goff, and $\mathrm{Yu}^{29}$ reported work in acid. DeSilvestro, Corrigan and Weaver ${ }^{30}$ took advantage of the SERS effect on Au to study the oxidation and reduction of electrodeposited $\mathrm{Ni}(\mathrm{OH})_{2}$ films on a $\mathrm{Au}$ substrate. The oxidation of $\mathrm{Ni}$ in near-neutral and alkaline solutions proceeds in two stages, the first leading to the formation of $\mathrm{Ni}^{+2}$ and the second to the formation of a higher valency state commonly thought of as $\mathrm{Ni}^{+3}$. The former leads to a very thin film of $\mathrm{Ni}(\mathrm{OH})_{2}$ in base 
and most probably to NiO in acid. No Raman spectroscopy study has definitely identified the surface film on $\mathrm{Ni}$ in alkali in the passive region but UV-visible reflectance measurements by Hahn et al. ${ }^{31}$ have been interpreted in terms of the species $\mathrm{Ni}(\mathrm{OH})_{2}$. The film appears to be at best a few monolayers thick. Desilvestro et al., ${ }^{30}$ obtained the Raman spectrum of five equivalent monolayers of $\mathrm{Ni}(\mathrm{OH})_{2}$ cathodically deposited on a roughened Au surface by employing the SERS technique. Jsing the $647.1 \mathrm{~nm}$ line of $\mathrm{K} \mathrm{Kr}^{+}$laser for excitation, they found a single band at $455 \mathrm{~cm}^{-1}$ which they identified as the $\mathrm{Ni}-\mathrm{OH}$ stretching mode. Oxidation of the $\mathrm{Ni}(\mathrm{OH})_{2}$ gave rise to two bands at 480 and 560 $\mathrm{cm}^{-1}$ which they identified as $\mathrm{Ni}-\mathrm{O}$ (rather than $\mathrm{Ni}-\mathrm{OH}$ ) vibrations due to the absence of a deuterium isotope effect. The oxidized form could only be detected in thicker layers usirg 488 and $514.5 \mathrm{~nm}$ excitation leading the authors to believe that the enhancement was by the resonance Raman effect. The further oxidation of $\mathrm{Ni}(\mathrm{OH})_{2}$ on $\mathrm{Ni}$ surfaces, in near-neutral and alkaline solutions, occurs in the transpassive potential region close to $\mathrm{O}_{2}$ evolution. We have studied the structure of this higher oxide form by LRS and XRD techniques and have assigned the two bands at 480 and $560 \mathrm{~cm}^{-1}$ to a structure consisting of layers of $\mathrm{NiO}_{2}$ with intercalated $\mathrm{H}_{2} \mathrm{O}$ and ions such as $\mathrm{K}^{+}, \mathrm{Na}^{+}, \mathrm{OH}^{-}, \mathrm{H}^{+}$, etc. between the layers. ${ }^{9}, 33$ We found that the spectra of various preparations ${ }^{37}$ of this higher oxide which have been referred to in the literature as $\mathrm{NiOOH}, \mathrm{Ni}_{2} \mathrm{O}_{3}, \mathrm{Ni}_{3} \mathrm{O}_{4}$ hydrates, and $\mathrm{NiO}_{2}$ yield the same vibrational spectrum (Fig. 8 ) and have very similar $\mathrm{X}$-ray powder patterns

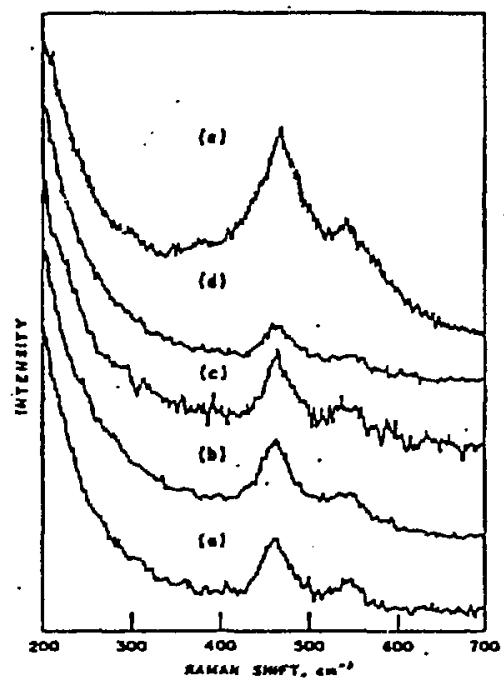

Figure 8. Raman spectra of various preparations of the higher oxide form of $\mathrm{Ni}$ (taken as powders pressed with $\mathrm{KBr}$ into a pellet), $\mathrm{Ar}^{+}$ laser, $514.5 \mathrm{~nm}$ line, Power $\sim 30-100 \mathrm{~mW}$. (a) $\beta$-NiOOH (after Glemser) $37 \mathrm{a}$; (b) $\gamma$-NiOOH (after Glemser); (c) $\mathrm{Ni}_{2} \mathrm{O}_{3} \cdot 2 \mathrm{H}_{2} \mathrm{O}$ (after Cairns) ${ }^{37 b}$; (d) $\mathrm{Ni}_{3} \mathrm{O}_{4} \bullet \mathrm{xH}_{2} \mathrm{O}$ (after Cairns); (e) $\mathrm{NiO}_{2}$ (purchased from Alfa). 
(Fig. 9). We concluded that these various forms of higher nickel oxide have the same layered $\mathrm{NiO}_{2}$ structure and differ only in the degree of structural disorder of the $\mathrm{NiO}_{2}$ slabs, the nature and amount of intercalated ions and $\mathrm{H}_{2} \mathrm{O}$ molecules. Such a structure is depicted in Fig. 10. We propose that the higher oxide form of $\mathrm{Ni}$ be called "hydrous
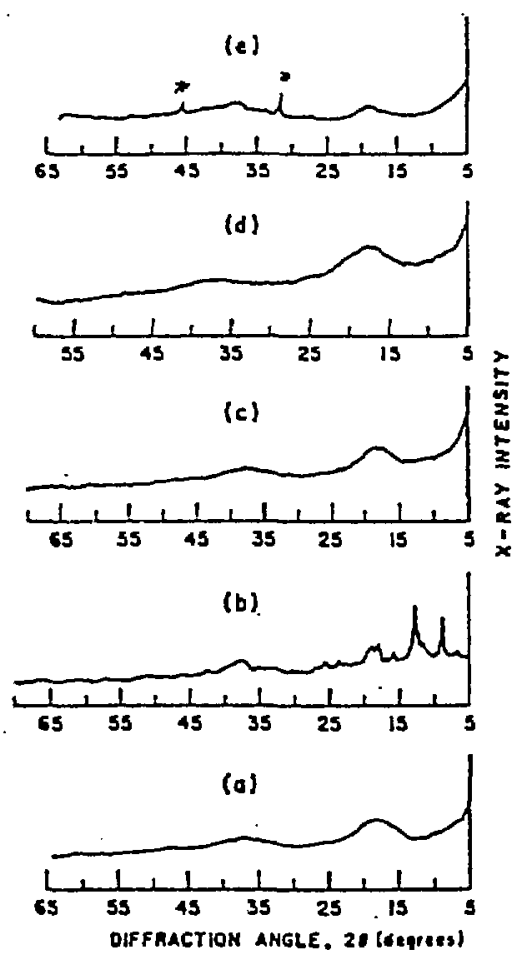

Figure 9. X-ray powder diffraction patterns of higher nickel oxide preparations. (a) $\beta-\mathrm{NiOOH}$ (prepared following Glemser) ${ }^{37 a}$; (b) $\gamma-\mathrm{NiOOH}$ (prepared following Glemser); (c) $\mathrm{Ni}_{2} \mathrm{O}_{3} \cdot 2 \mathrm{H}_{2} \mathrm{O}$ (prepared following Cairns) ${ }^{37 b}$; (d) $\mathrm{Ni}_{3} \mathrm{O}_{4} \cdot \mathrm{xH}_{2} \mathrm{O}$ (prepared following Cairns); (e) $\mathrm{Ni}_{2} \mathrm{O}_{3} \cdot \mathrm{xH}_{2} \mathrm{O}$ (Aldrich, * $\mathrm{NaCl}$ lines)

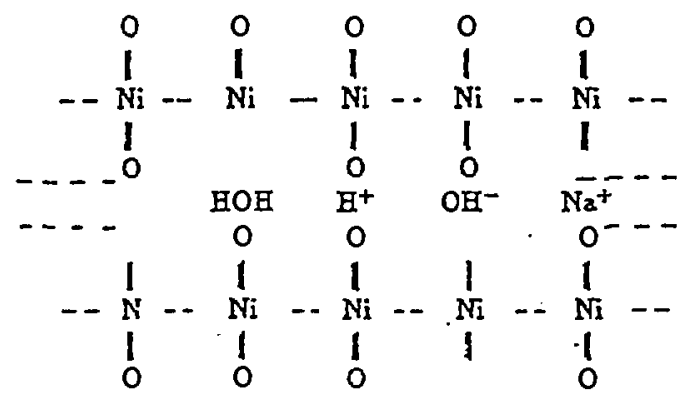

Figure 10. Proposed structure of "hydrous $\mathrm{NiO}_{2} \mathrm{film}^{\mathrm{f}}$ 
$\mathrm{NiO}_{2}$ " instead of $\mathrm{NiOOH}$ as has been done for many years. The maximum valency of $\mathrm{Ni}$ in such a compound is +4 , although the actual material prepared in the laboratory, most probably, consists of a mixture of $\mathrm{Ni}^{+2}$ and $\mathrm{Ni}^{+4}$. UV-visible spectroscopic evidence for the existence of $\mathrm{Ni}^{+4}$ nas been presented by Corrigan and Knight. 34

The composition of corrosion films on $\mathrm{Ni}$ in acid solutions has been studied by Delichere, et al. 29 and also in our laboratory. 32,35 The former investigators identified the passive film on $\mathrm{Ni}$ in $1 \mathrm{M} \mathrm{H}_{2} \mathrm{SO}_{4}$ solution to be $\mathrm{NiO}$; in the region of secondary passivity, they assumed that $\mathrm{Ni}_{2} \mathrm{O}_{3}$ is present. We have also obtained a spectrum of the surface film on $\mathrm{Ni}$ anodized in the transpassive region in $0.05 \mathrm{M} \mathrm{H}_{2} \mathrm{SO}_{4}{ }^{32}$ but have not been able to assign it unequivocally to any oxide of $\mathrm{Ni}$. However, in concentrated $\mathrm{H}_{2} \mathrm{SO}_{4}$ solution, our results ${ }^{35}$ indicate that the corrosion film formed in the passive region is composed of $\mathrm{NiSO}_{4} \cdot \mathrm{H}_{2} \mathrm{O}$. This assignment was confirmed by XRD studies.

A number of studies have dealt with the in-situ identification of the passive film on iron by LRS. 10,11,36-38 Thibeau et a1. ${ }^{9}$ obtained the spectrum of a number of iron oxides which they anticipated to be the corrosion products of iron. The $\frac{i r}{40}$ group also studied the oxidation of $\mathrm{Fe}_{3} \mathrm{O}_{4}$ on iron and steel surfaces. ${ }^{40}$ Nazri ${ }^{36}$ studied extensively the dissolution and film formation on iron in bcrate solutions using cyclic voltammetry (CV) and rotating ring disc electrode (RRDE) techniques. He used LRS in an attempt to identify the passive film on Fe. The film showed several bands at low frequency $\left(200-800 \mathrm{~cm}^{-1}\right)$ which did not match those of the known oxides or oxyhydroxides of iron. Froelicher ${ }^{11}$ et al. employed very fast oxidation-reduction cycles (scan rate $=6$ $\mathrm{v} / \mathrm{sec}$ ) in order to increase the thickness of oxide films on iron in a number of solutions from $0.5 \mathrm{M} \mathrm{H}_{2} \mathrm{SO}_{4}$ to $1 \mathrm{M} \mathrm{KOH}$. Thick films ( 100 to $200 \mathrm{~A})$ were also produced by polarization maintained for a long time ( $\sim 2$ days). The films were thus artificially thicker than those of the passive films. For an iron sample polarized for 60 hours in $0.5 \mathrm{M}$ $\mathrm{H}_{2} \mathrm{SO}_{4}$ solution, they obtained a kaman spectrum which corresponded to a mixture of $\mathrm{Fe}_{2} \mathrm{O}_{3}$ and $\mathrm{Fe}_{3} \mathrm{O}_{4}$. Dünnwald, Lossy, and otto ${ }^{10}$ appear to have been the first to make a definite in-situ LRS identification of the composition of the passive film on $\mathrm{Fe}$ in $\mathrm{KOH}$ solution. They observed bands at 543 and $674 \mathrm{~cm}^{-1}$ in-situ but only after cycling the electrode 17 times from -1.3 to $0.5 \mathrm{~V}$ vs $S C E$ at a scan rate of $1 \mathrm{mV} / \mathrm{sec}$. These bands correspond to those of $\mathrm{Fe}_{3} \mathrm{O}_{4}$. Continued cycling of the electrode (over 20 cycles) resulted in the appearance of a reddish brown "rusty" coating which yielded bands at $251,303,390,482,552,682$, and 1003 $\mathrm{cm}^{-1}$. This set of bands resembled closely those for $a-F e 00 H$. The coating could be washed off by a strong water jet, after which the sample appeared metallic again. The spectrum taken after washing corresponded to that of $\mathrm{Fe}_{3} \mathrm{O}_{4}$ once again. This is good evidence that the $\alpha-\mathrm{FeOOH}$ is an overlayer on top of the $\mathrm{Fe}_{3} \mathrm{O}_{4}$ which Dünnwald et al. believed to constitute the passive film. The existence of such an overlayer comes about due to the oxidation of $\mathrm{Fe}^{+2}$ species in the solution and the resulting deposition on the electrode. Such a mechanism has been proposed by Nazri and Yeager. 41 It is also worthwhile to note here that Dünnwald et al. found that the same spectrum of $\mathrm{Fe}_{3} \mathrm{O}_{4}$ is obtained when the sample is allowed to stand in ambient air for one 
day. Thus, they concluded that exposure to gaseous $\mathrm{O}_{2}$ is not criticai in their experiments.

Hugot Le-Goff and Palotta $a^{38 a, b}$ reported results of in-situ LRS of $\mathrm{Fe}$ in $1 \mathrm{M} \mathrm{H}_{2} \mathrm{SO}_{4}$. Following 8 hours of anodic polarization, they found a slight increase in the reflectance of the electrode surface and were able to obtain a spectrum which corresponded to a mixture of $a-\mathrm{Fe}_{2} \mathrm{O}_{3}$ and $\mathrm{Fe}_{3} \mathrm{O}_{4}$. The film thickness was measured by nuclear microanalysis to be about $10 \mathrm{~nm}$. The authors equated the induction time needed to observe a spectrum to the time needed to age the film to the point where the "gel" structure developed into a more crystalline form.

Thanos 12 took advantage of the SER effect exhibited by small Ag particles to study the corrosion products of $\mathrm{Fe}$ and Fe-9z $\mathrm{Cr}$ alloy. He electrodeposited $\mathrm{Ag}$ on pre-passivated $\mathrm{Fe}-\mathrm{Cr}$ alloy electrodes. He found that thicker corrosion products on $\mathrm{Fe}$ could be formed in $\mathrm{HNO}_{3}$ by what he termed a reductive precipitation at $-0.8 \mathrm{~V}$ vs $\mathrm{SCE}$. $\mathrm{Fe}_{3} \mathrm{O}_{4}$ was identified at stationary electrodes while $\mathrm{Fe}(\mathrm{OH})_{2}$ was found on rotated ones. He observed a broadening of the $\mathrm{Fe}_{3} \mathrm{O}_{4}$ band at $680 \mathrm{~cm}^{-1}$ upon oxidation of $\mathrm{Fe}(\mathrm{OH})_{2}$ which he attributed to the formation of higher defect oxides and hydroxides.

We have also studied the corrosion behavior of iron in phosphate solutions 42 from $\mathrm{pH} 1.6$ to 11.9 . Cyclic voltametry measurements showed mostly active dissolution in acid solutions of $0.1 \mathrm{M} \mathrm{H}_{3} \mathrm{PO}_{4}$ and $\mathrm{NaH}_{2} \mathrm{PO}_{4}$; complete passivity is observed in alkaline $0.1 \mathrm{M} \mathrm{Na}_{2} \mathrm{HPO}_{4}$ and $\mathrm{Na}_{3} \mathrm{PO}_{4}$ ( $\mathrm{Fig}$. 11). The composition of the corrosion films formed in the

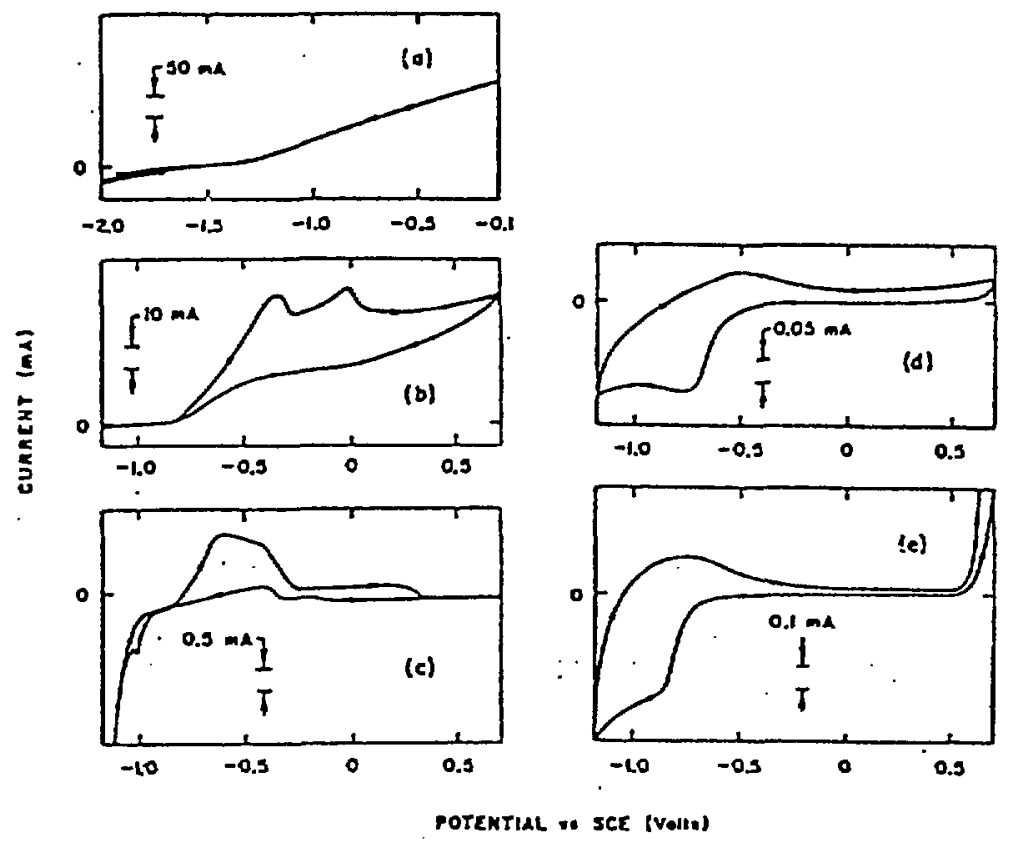

Figure 11. Cyclic voltammograms of iron in aerated phosphate solutions; (a) $0.1 \mathrm{M} \mathrm{H}_{3} \mathrm{PO}_{4}$ ( $\mathrm{pH} \mathrm{1.6);} \mathrm{(b)} 0.1 \mathrm{M} \mathrm{NaH}_{2} \mathrm{PO}_{4}$ ( $\mathrm{pH} \mathrm{4.4);} \mathrm{(c)} 1: 1$ volume mixture of $0.10 \mathrm{M} \mathrm{Na}_{2} \mathrm{HPO}_{4}$ and $0.16 \mathrm{M} \mathrm{NaH}_{2} \mathrm{PO}_{4}$ ( $\mathrm{pH} 6.4$ ); (d) $0.1 \mathrm{M}$ $\mathrm{Na}_{2} \mathrm{HPO}_{4}(\mathrm{pH} 8.7)$; (e) $0.1 \mathrm{M} \mathrm{Na}_{3} \mathrm{PO}_{4}(\mathrm{pH} 11.9) ; \mathrm{All}$ scan rate $=10$ $\mathrm{mV} / \mathrm{sec}$. 
latter solutions was determined by LRS to consist mainly of $\mathrm{Fe}_{3} \mathrm{O}_{4}$ (bands at 556 and $680 \mathrm{~cm}^{-1}$ ) with $\mathrm{PO}_{4}=$ (944 and $1068 \mathrm{~cm}^{-1}$ ) incorporated into the lattice structure of the film (Fig. 12). In acidic $0.1 \mathrm{M}$ $\mathrm{NaH}_{2} \mathrm{PO}_{4}$, multilayer film formation occurs. Open circuit corrosion

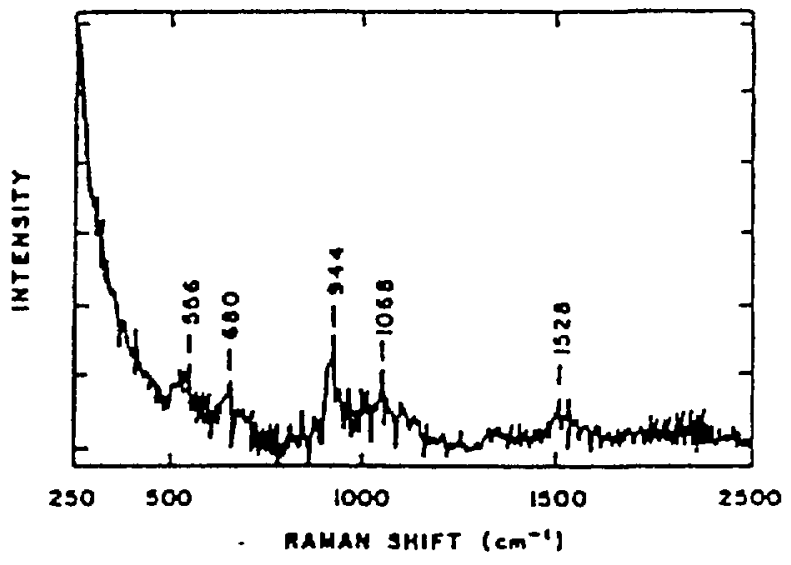

Figure 12. Raman spectrum of corrosion film on iron in $0.1 \mathrm{M} \mathrm{Na}_{3} \mathrm{PO}_{4}$ $(\mathrm{pH} 11.9)$ after potential hold at $0.4 \mathrm{~V}$ for 19 hours.

leads to the formation of a surface film whose in situ spectra are shown in Figs. 13a and $13 \mathrm{~b}$ after two hours and two days of standing, respectively. The bands at 1020 and $1346 \mathrm{~cm}^{-1}$ are due to material on the surface while those at 878 and $1082 \mathrm{~cm}^{-1}$ are from $\mathrm{PO}_{4} \equiv$ in solution. It is interesting to note the change in spectra after two days immersion. The surface film was examined microscopically and found to consist of two layers: a very thin greyish-white outer layer and a bluish undercoating, which is adherent to the electrode surface. A composite Raman spectrum of the duplex film is shown in Fig. 13c while that of the bluish inner layer is shown in Fig. 13d. X-ray diffraction analysis of the latter shows the structure to be the same as that of the mineral vivianite or $\mathrm{Fe}_{3}\left(\mathrm{PO}_{4}\right)_{2} \cdot 8 \mathrm{H}_{2} \mathrm{O}$. The outer layer could not be analyzed by XRD, but we believe that it is the phase $\mathrm{Fe}\left(\mathrm{H}_{2} \mathrm{PO}_{4}\right)_{2}$ in line with predictions of the Pourbaix diagram.

Finally, in a related study Keiser et al. ${ }^{43,44}$ studied the ambient oxidation of $\mathrm{Fe}_{3} \mathrm{O}_{4}$ on iron and steel surfaces, as well as the electrochemical reduction of $\alpha, \gamma, \delta$, and amorphous $\mathrm{FeOOH}$ in aqueous sulfate solution. They found that $\mathrm{Fe}_{3} \mathrm{O}_{4}$ was oxidized to $\gamma$-FeOOH which converted to $\alpha-\mathrm{FeOOH}$ after several weeks. The electrochemical reduction of amorphous $\gamma$ - and $\delta$ - $\mathrm{FeOOH}$ on weathering steel substrates produced $\mathrm{Fe}_{3} \mathrm{O}_{4}$.

\subsection{Metal Alloys}

A number of papers have dealt with the LRS study of surface films produced by atmospheric oxidation of metal alloys $36,39,45,46$; very little work, however, has been done to identify the corrosion film formed in aqueous solution environments. Thanos ${ }^{12}$ attempted to obtain in-situ spectrum of $\mathrm{Fe}-9 \% \mathrm{Cr}$ alloy without much success. However, following 


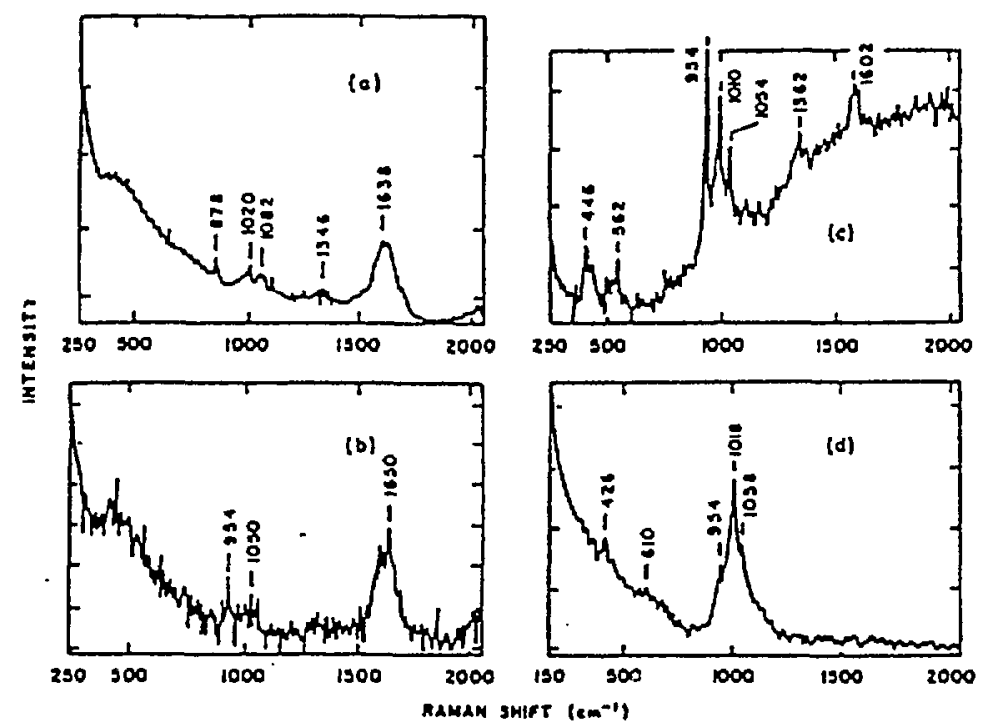

Figure 13. Raman spectra of corrosion films on iron in $0.1 \mathrm{M} \mathrm{NaH}_{2} \mathrm{PO}_{4}$, $\mathrm{Ar}^{+}$laser, $514.5 \mathrm{~nm}$ line, Power $\simeq 50$ to $150 \mathrm{~mW}$.

electrodeposition of $\mathrm{Ag}$ on the prepassivated electrode (to take advantage of the SER effect), he was able to observe Raman active bands of thin films of oxides and hydroxides on the passivated alloy. A bani due to $\mathrm{Fe}_{3} \mathrm{O}_{4}$ was observed as in the case of $\mathrm{Fe}$ which became broad at potentials greater than about 0 to $0.2 \mathrm{~V}$ vs SCE. Such broadening was explained by the author to be due to lattice disorder because of random distribution of $\mathrm{Fe}^{+2}$ and $\mathrm{Fe}^{+3}$ ions.

Thierry et al. 47 also studied the anodic corrosion films formed on single crystals of $\mathrm{Fe}-\mathrm{Cr}$ and $\mathrm{Fe}-\mathrm{Cr}-\mathrm{Mo}$ alloys using LRS in combination with $X$-ray Photoelectron Spectroscopy (XPS) and nuclear microanalysis. Films were formed in the passive and transpassive regions in $1 \mathrm{M} \mathrm{KOH}$. The former had a thickness in the range of 5 to $6 \mathrm{~nm}$ and was determined to most 1 ikely be a mixed $\alpha-(\mathrm{Fe}, \mathrm{Cr}){ }_{2} \mathrm{O}_{3}$ phase. The transpassive film was found to be 5 to $25 \mathrm{~nm}$ thick and was formed in various stages. The latier stages were identified to include the formation of $5 \mathrm{~nm}$ of $\alpha$ $(\mathrm{Fe}, \mathrm{Cr})_{2} \mathrm{O}_{3}$, followed by $10 \mathrm{~nm}$ of $\mathrm{Fe}-\mathrm{Cr}$ spinel, and a top layer of $10 \mathrm{~nm}$ $\gamma-\mathrm{FeOOH}$. They found no significant differences in spectra from corrosion films formed on Fe-Cr and Fe-Cr-Mo single crystals.

A study of $\mathrm{Ni}-10 \mathrm{~K}$ Mo alloy has been reported by Delichere et al. 29 Polarization of the alloy in $1 \mathrm{M} \mathrm{H}_{2} \mathrm{SO}_{4}$ solution showed the existence of a $\mathrm{NiO} f i l m$ over a more extended range than was the case of pure $\mathrm{Ni}$ in the same solution.

\subsection{Raman Spectroscopy Studies of Corrosion Inhibitors}

The inhibition of corrosion through the addition of small quantities of organic and inorganic substances to the solution is of great practical importance. Considerable research activity goes on in this field ${ }^{49}$ but 
few have taken advantage of the potential of LRS in elucidating the mechanism of corrosion inhibition. A number of theories have been proposed to explain the action of inorganic inhibitors, and these theories most probably apply to organic ones also. Among these are the chemical reaction theory, electrochemical polarization theory, adsorption theory, and electrostatic polarization theory. 50 Whereas one mode of action may be dominant in a certain case, it is not always a straightforward process to delineate this and it is likely that quite often several of the mechanisms are operative to various extents.

Kester, Furtak, and Bevolo ${ }^{5}$ first utilized the SER effect to study the structure of benzotriazole (BTA) on $\mathrm{Cu}$. They obtained spectra of BTA at different potentials but were unable to assign the observed frequencies to the various normal modes of vibration of the molecules. They established that the observed signals were due to SER scattering. They also observed a hysteresis in the Raman intensity as a function of applied potential which they attributed to a bonding rearrangement of the molecules in the protective surface layer. They further noted that the structure of the surface complex of BTA with Cu was altered by laser illumination during anodization which resulted in better protective ability of the coating.

Thierry and Leygraf ${ }^{1 b}$ studied the adsorption of $1,2,4$ triazole and imidazole on microlithographically prepared $\mathrm{Cu}$ surfaces at the corrosion potential. They compared their spectra with those on Cu surfaces subjected to oxiolation-reduction cycles (ORCs) and found the spectra to be very similar, suggesting that the ORC had no influence on the orientation or possible dissociation of the molecules on $\mathrm{Cu}$. The spectra were also similar to those in ethanol, indicating that the molecules did not undergo any dissociation upon adsorption. They were able to obtain an intense spectrum of the $1,2,4$ trjazole on microlithograghed $\mathrm{Cu}$ (with particle size of 2000 to $3000 \mathrm{~A}$ and periodicity of $5500 \mathrm{~A}$ ) at the corrosion potential of $-150 \mathrm{mV}$ vs SCE in $0.1 \mathrm{M} \mathrm{NaCl}$; they did not, however, observe a spectrum on a smooth $\mathrm{Cu}$ surface which was polished with diamond paste. This demonstrated that an ORC is not necessary to obtain SERS but microscopic surface roughness appears to be essential.

Loo et a1. 52 also studied the adsorption of some imidazoles on $\mathrm{Cu}$ and $\mathrm{Ag}$ electrodes in $0.1 \mathrm{M} \mathrm{KCl} \mathrm{(pH} \mathrm{7.7).} \mathrm{They} \mathrm{found} \mathrm{that} \mathrm{whereas} \mathrm{the}$ Raman spectrum of free imidazole exhibits complex spectral features in the region between 2500 and $3100 \mathrm{~cm}^{-1}$ due to intermolecular hydrogen bonding, the SER spectrum does not. Thus, they concluded that the imidazole is adsorbed on $\mathrm{Cu}$ and $\mathrm{Ag}$ surfaces through its nitrogen atom with the five membered ring perpendicular to the substrate; otherwise, hydrogen bonding would occur for flatly oriented molecules giving rise to a more complex spectrum. Loo ${ }^{53}$ also studied the adsorption of thiourea on $\mathrm{Cu}$ and $\mathrm{Ag}$ electrodes in $0.1 \mathrm{M} \mathrm{KCl}$ solutions. The solution spectrum of thiourea, $\mathrm{SC}\left(\mathrm{NH}_{2}\right)_{2}$ shows bands at $409,479,733,1096$, and $1404 \mathrm{~cm}^{-1}$. Upon adsorption of the molecule on a $\mathrm{Ag}$ or $\mathrm{Cu}$ surface, the $733 \mathrm{~cm}^{-1}$ band showed a large red shift of $\sim 30 \mathrm{~cm}^{-1}$ and exhibited a large reduction in relative intensity. This band was assigned to a $\mathrm{C}-\mathrm{S}$ stretching frequency; since it was the most strongly affected band, Loo concluded that the thiourea is bonded to the $\mathrm{Cu}$ or Ag surface via the $\mathrm{S}$ 
atom. X-ray, IR, and Raman studies suggest that the electronic structure of the thiourea may be represented by equal contributions from the resonance hybrid structures, $a, b$, and $c$, shown below.

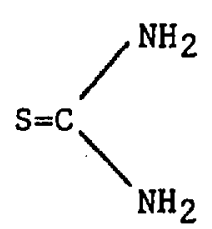

(a)

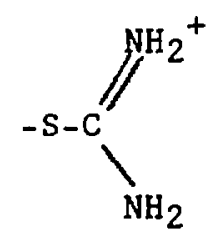

(b)

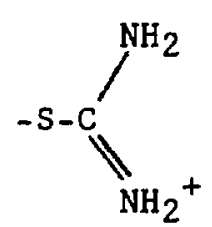

(c)

Loo also found a low frequency vibration at $221 \mathrm{~cm}^{-1}$ for thiourea adsorbed on $\mathrm{Ag}$ and one at $228 \mathrm{~cm}^{-1}$ for adsorption on $\mathrm{Cu}$; these he attributed to the metal adatom-thiourea complex vibration rather than to $\mathrm{Ag}-\mathrm{Cl}$ or $\mathrm{Cu}-\mathrm{Cl}$ complex, respectively. The metal thiourea complex was proposed to be $\mathrm{AgSC}\left(\mathrm{NH}_{2}\right)_{2}{ }^{+} \mathrm{CI}^{-}$and $\mathrm{CuSC}\left(\mathrm{NH}_{2}\right)_{2}{ }^{+} \mathrm{Cl}{ }^{-}$.

Rubin, Gutz, and co-workers 54 also studied the adsorption of benzotriazole (BTA) on a $\mathrm{Cu}$ electrode as a function of potential in different chloride solutions at various pHs. They concluded that the protective film on $\mathrm{Cu}$ in the presence of BTA is copper (I) beazotriazoiate or $\mathrm{CuC}_{6} \mathrm{H}_{4} \mathrm{~N}_{3}$ [Cu(I)BTA]. The material is polymeric with the structure,

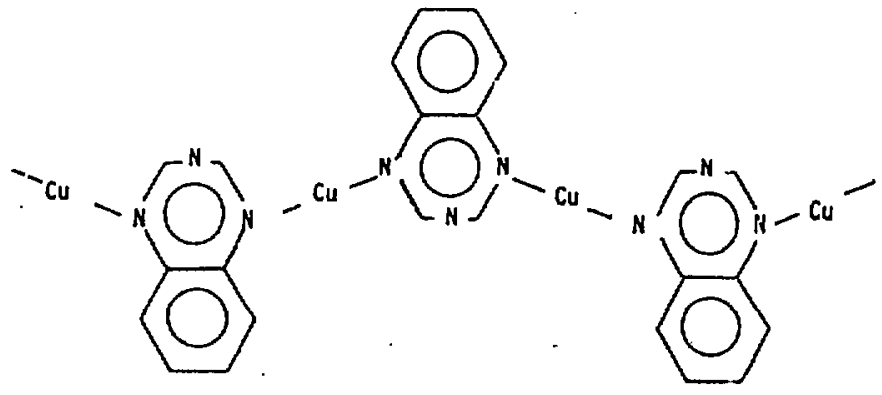

The CuBTA polymer film grows from a ghemisorbed monolayer to form a protective layer which is 3000-4000 A thick. The growth of such thick films involves transport of $\mathrm{Cu}$ ions through the layer. The $\mathrm{Cu}$ ions are then thought to react with benzotriazolate anions at the solid/liquid interface to produce more polymer.

Thierry and Leygraf ${ }^{55}$ compared the inhibitor properties of five structurally related $\mathrm{N}$-heterocyclic molecules towards the corrosion of $\mathrm{Cu}$ in NaCl solutions. Polarization resistance measurements in 0.01 and $0.1 \mathrm{M} \mathrm{NaCl}$ solutions showed that the percentage inhibition efficiency increases in the order mercapto-benzimidazole (MCBIA) > benzimidazole (BIA)> methylbenzimidazole (MBIA)> hydroxybenzimidazole (HBIA). Raman spectral measurements showed all the molecules to be adsorbed on the $\mathrm{Cu}$ surface without dissociation. For BTA and BIA, they found significantly larger differences in frequency shifts for vibrational modes originating from the triazole or imidazole part of the molecule than for modes originating from the benzene part. They interpreted this to mean 
that adsorption of these molecules occurs via the triazole and imidazole part and most likely through interaction of all three nitrogen or carbon atoms with the $C u$ substrate. MCBIA, HBIA, and MBIA, on the other hand, showed no preferential enhancement in intensity or frequency shift originating from the imidazole part; therefore, they are oriented differently than BTA or BIA. AC impedance measurements were used to obtain double layer capacitances of $\mathrm{Cu}$ in $0.1 \mathrm{M} \mathrm{NaCl}$ with added $5 \mathrm{mM}$ inhibitors. The measured capacitances decreased in the order BIA< BTA< MCBIA; the values also decreased with increasing anodic potential (in the range of -700 to $-100 \mathrm{mV}$ vs SCE). Thus, the more efficient inhibitor exhibited lower double layer capacitance which the authors attributed to a thicker polymer layer. The difference in inhibition efficiency of the five molecules investigated was explained by the number and type of functional groups or atoms in the triazole or imidazole ring that interact with the $\mathrm{Cu}$. This interaction was thought to involve $\mathrm{N}-\mathrm{N}-\mathrm{N}$ and $\mathrm{N}-\mathrm{C}-\mathrm{N}$ in the case of BTA and BIA, N and $S$ from the $\mathrm{N}-$ $H$ and $S-H$ groups in the case of MCBIA, and only $N$ from the $\mathrm{N}-\mathrm{H}$ group in the case of HBIA and MBIA. From the behavior of the molecules studied, the inhibiting efficiency of various atoms in functional groups follows the order $\mathrm{S}>\mathrm{N}>0$.

Ohsawa and süetaka 56 studied the intensity enhancement and spectral change in the Raman scattering of mercaptobenzotriazole (MCBTA) adsorbed on a $\mathrm{Ag}$ electrode fruis $0.1 \mathrm{M} \mathrm{Na}_{2} \mathrm{SO}_{4}$ solution. They concluded that MCBTA is adsorbed on $A B$ in the form of ionized thiol. They observed dramatic changes in Raman intensity in changing the concentration of MCBTA at $1 \times 10^{-8} \mathrm{M}$ and $1 \times 10^{-6} \mathrm{M}$. They ascribed the former to a change in orientation of adsorbed molecules and the latter to the formation of a multilayered film. They found the largest intensity enhancement to be for the species adsorbed in normal orientation with respect to the surface. The addition of $\mathrm{I}^{-}, \mathrm{Br}^{-}$, or $\mathrm{Cl}^{-}$resulted in the conversion of the thiol species to the thione form. They believe that this conversion and the occupation of adsorbed sites by halide ions is related to the effect of halide in impeding the protective action of MCBA.

\subsection{High Temperature Raman Spectroelectrochemistry}

The extension of LRS techniques for in-situ measurements in high-temperature/high-pressure (HTHP) aqueous solution environments is of considerable practical interest. Such conditions are encountered in a number of applications, such as, studies on the stress corrosion cracking of metals used in nuclear reactor coolant systems, thermodynamic processes in geothermal environments, general and localized corrosion in industrial boiler water and condenser systems, etc. These facilities normally operate at temperatures above $200^{\circ} \mathrm{C}$ and pressures over 1000 psi. LRS measurements in-situ on corrosion films produced under such environmental conditions require the construction of special apparatus; 57,58 a spectro-electrochemical cel1 for HTHP application is shown in Fig. 14. The cell body (A) is made of titanium for corrosion resistance and has dimensions of $5.7 \mathrm{~cm}$ diameter by $7.6 \mathrm{~cm}$ long. It is 

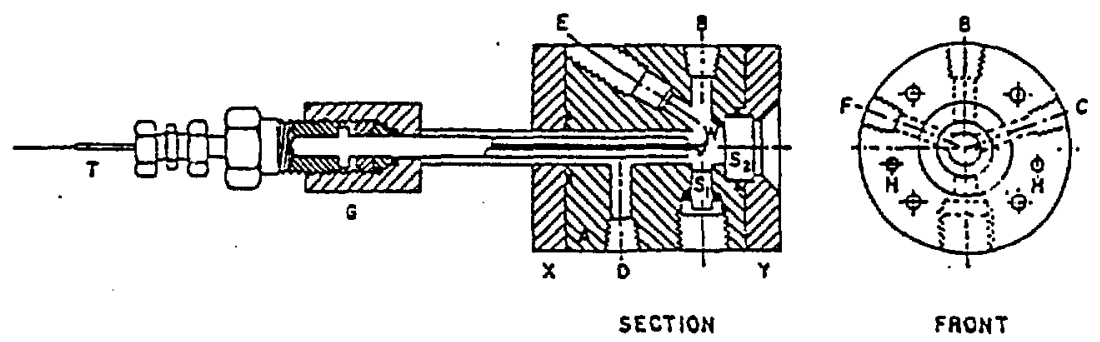

A - Titanium Cell Body
B - Counter Electrode Port
C - Reference Electrode and
Electrolyte Exit Port
D - Electrolyte Inlet
E - Light Exit or Thermocouple Port
F - Viewing Port
G - Shait Seal

A - Titanium Cell Body

B - Counter Electrode Port

- Reference Electrode and

- Electrolyte Inle:

$F$ - Viewing Porl

G - Shaft Seal

\author{
H - Heaters \\ $S_{1}$ - Sapphire Window for \\ Laser Beam Inlet \\ $S_{2}$ - Sapphire Window for \\ Scattered Raman Light \\ $T$ - Teflon Sheath on \\ Electrode Lead \\ W - Working Electrode
}

Figure 14. Cell for in-situ laser Raman spectroscopy and electrochemical studies of high-temperature/high-pressure aqueous solutions.

bolted to the end flanges " $\mathrm{X}$ " and "Y" with Teflon 0 -ring seals between the parts. Provision is made to admit the laser beam through a port fitted with a $0.95 \mathrm{~cm}$ dia. by $1.11 \mathrm{~cm}$ thick sapphire window $\left(\mathrm{S}_{1}\right)$; the inelastically scattered light is collected through a second sapphire window $\left(s_{2}\right)$ which is $2.22 \mathrm{~cm}$ dia. by $0.95 \mathrm{~cm}$ thick. The corrosion sample is normally prepared in the form of a $0.47 \mathrm{~cm}$ dia. disc and is used as the working electrode (W). In one study, 16,57 for example, lead was deposited on a nickel disc by splat cooling from a molten lead bath. The electrode connection is made through a $0.16 \mathrm{~cm}$ nickel rod sheathed in heat-shrinkable Teflon (T); it is held inside a $0.635 \mathrm{~cm}$ cylindrical shaft which can be moved back and forth or rotated through the use of a especially designed shaft seal $(G)$. These movements are necessary for proper alignment of the electrode surface with respect to the laser beam. The counder electrode is introduced through either port $B$ or $E$; we have used a loop consisting of several turns of Pt. wire. Either one of ports $B$ or $E$ is fitted with a thermocouple for temperature measurement. A silver-silver sulfate $\left(\mathrm{Ag} / \mathrm{Ag}_{2} \mathrm{SO}_{4}\right)$ reference electrode is introduced through port $C$. This electrode is constructed in a manner similar to the $\mathrm{Ag} / \mathrm{AgCl}$ quasi-reference described by Danielson. ${ }^{9}$ It has a potential of $0.041 \mathrm{~V}$ with respect to $\mathrm{Hg} / \mathrm{Hg}_{2} \mathrm{SO}_{4}$ at $25^{\circ} \mathrm{C}$. We have calibrated it by comparison with a $\mathrm{Ag} / \mathrm{AgCl}$ reference up to a temperature of $290^{\circ} \mathrm{C}$.

The cell is heated using two "Calrod" heater cartridges (H) which are imbedded in the cell body. Two thermocouples are similarly mounted. All seals (black shading in Fig. 14) are made of Teflon; metalreinforced Teflon rings, obtained commercially (Bal-Seal Engineering Co., CA), are used for the shaft-seal and to seal the sapphire windows. 
A viewing port (F) fitted with a sapphire window is also provided to facilitate positioning of the working electrode and the cell inside the illumination chamber of the spectrometer.

The electrolyte solution is refreshed in order to prevent buildup of corrosion products inside the cell; it flows through the cell, entering at port $D$ and exiting at $C$. The recirculation system is shown in Fig. 15. The electrolyte solution is prepared in a stainless steel reservoir ( $R$ ) and deoxygenated by sparging with dry nitrogen. The

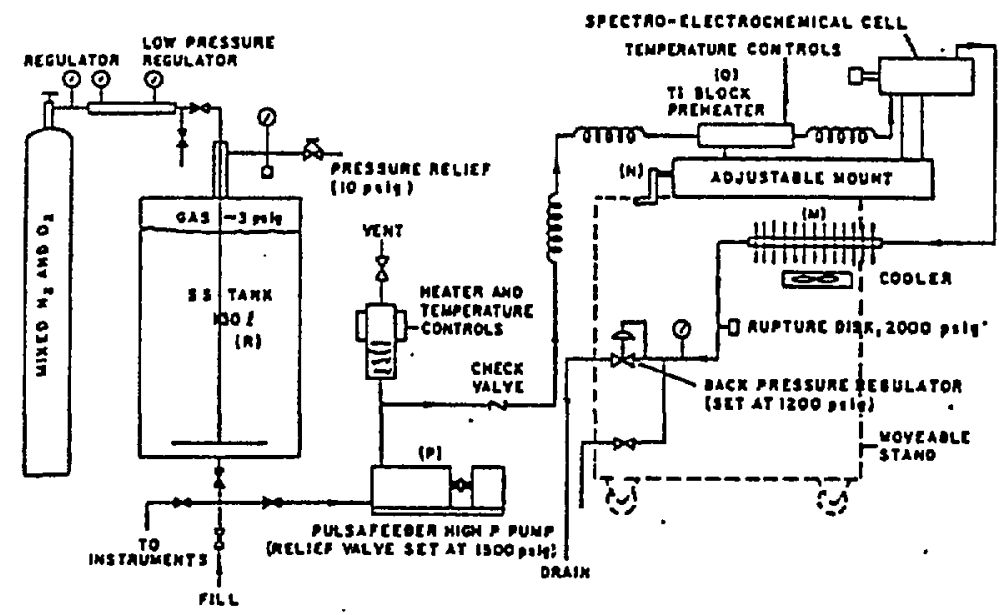

Figure 15. High-temperature/high-pressure spectroelectrochemical facility.

solution is then pumped into the cell using a high-pressure pump (P) after passing through a $\mathrm{Ti}$ block preheater (Q). The effluent from the cell is cooled by passing it through an air-cooled heat exchanger (M) and then discarded into the drain. The spectro-electrochemical cell and $\mathrm{Ti}$ block preheater are mounted on a movable cart fitted with a screw drive system (N) which allows positioning of the cell in the illumination chamber of the Raman spectrometer. The electrochemical equipment and Raman instrument used have been described previously ${ }^{9}$ and are shown schematically in Fig. 2 .

Initial testing of the HTHP facility was undertaken through a study of the anodic corrosion of lead in $7 \times 10^{-4} \mathrm{M} \mathrm{Na}_{2} \mathrm{SO}_{4}$ (i.e., 100 ppm $\mathrm{Na}_{2} \mathrm{SO}_{4}$ solution, $\mathrm{pH}=6.1$ ). The choice of this system was based on our previous studies $(5)$ which showed that the corrosion of lead results in the formation of a surface layer of $\mathrm{PbSO}_{4}$ that has a large cross section for Raman scattering. Other studies 60 also indicated that the $\mathrm{PbSO}_{4} \mathrm{film}$ is stable at high temperatures. The low concentration (100 ppm) of $\mathrm{Na}_{2} \mathrm{SO}_{4}$ was designed to simulate the level of impurities often present in reactor coolant water. Fig. 16 shows cyclic voltammograms of $\mathrm{Pb}$ in $7 \times 10^{-4} \mathrm{M} \mathrm{Na}_{2} \mathrm{SO}_{4}\left(\mathrm{O}_{2}\right.$-free $)$ at $25^{\circ} \mathrm{C}$ and $280^{\circ} \mathrm{C}$. It is evident that typical active dissolution-passivation behavior is observed at both temperatures; the voltammetric behavior is basically the same at intermediate temperatures. Reversibility is apparent from the presence of the corresponding cathodic wave. Fig. 17 shows Raman spectra 


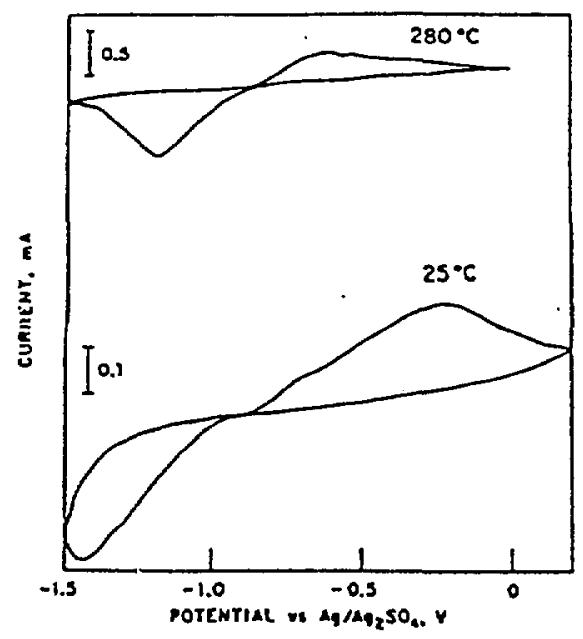

Figure 16. Cyclic voltammogram of $\mathrm{Pb}$ in $7 \times 10^{-4} \mathrm{M} \mathrm{Na}_{2} \mathrm{SO}_{4}$ at $25^{\circ}$ and $280^{\circ} \mathrm{C}$. Scan rate $=1 \mathrm{mV} / \mathrm{sec}$.

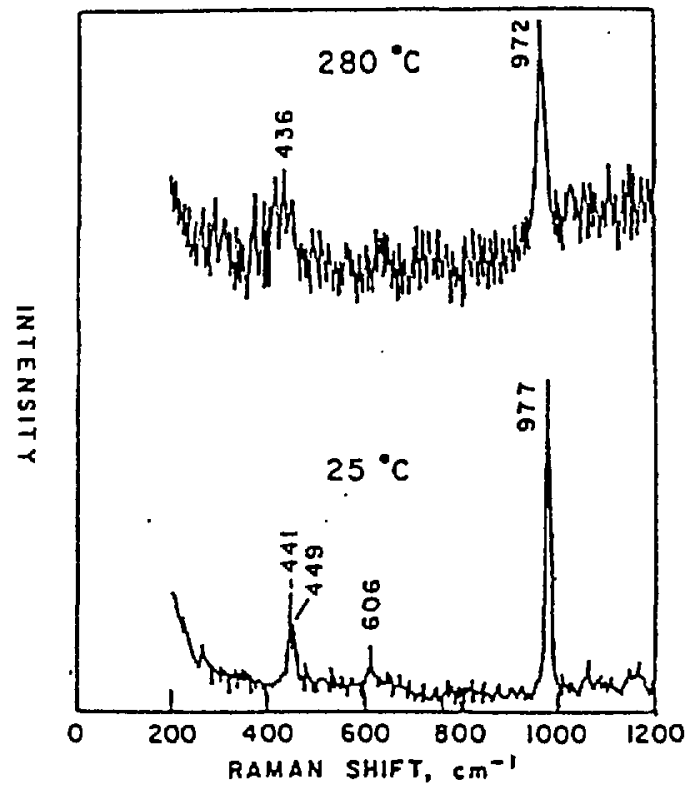

Figure 17. In-situ Raman spectra of passive film on $\mathrm{Pb}$ anodized at $-0.1 \mathrm{~V}$ vs $\mathrm{Ag} / \mathrm{Ag}_{2} \mathrm{SO}_{4}$.

obtained in-situ at 25 and $280^{\circ} \mathrm{C}$ for the passive film formed by constant potential anodization at $-0.10 \mathrm{~V}$ vs $\mathrm{Ag} / \mathrm{Ag}_{2} \mathrm{SO}_{4}$. Assuming that all the charge under the cathodic wave in Fig. 16 is due to the reduction of the passive film, we estimated the film thickness to be on the order of $1-3 \mu \mathrm{m}$. Based on the observed vibrational spectrum, the anodic corrosion $f$ ilm is identified as $\mathrm{PbSO}_{4}$, consistent with the spectrum of 
this material observed in our previous work. ${ }^{6}$ The same spectra are obtained upon anodization at intermediate temperatures. We observed no significant shift in band frequencies but found a steady decrease in signal-to-noise ratio as the temperature was raised from 20 to $280^{\circ} \mathrm{C}$. We have also observed the frrmation of a surface film on corrosion at the open-circuit voltage (OCV) of about $-0.96 \mathrm{~V}$ (Fig. 18). The

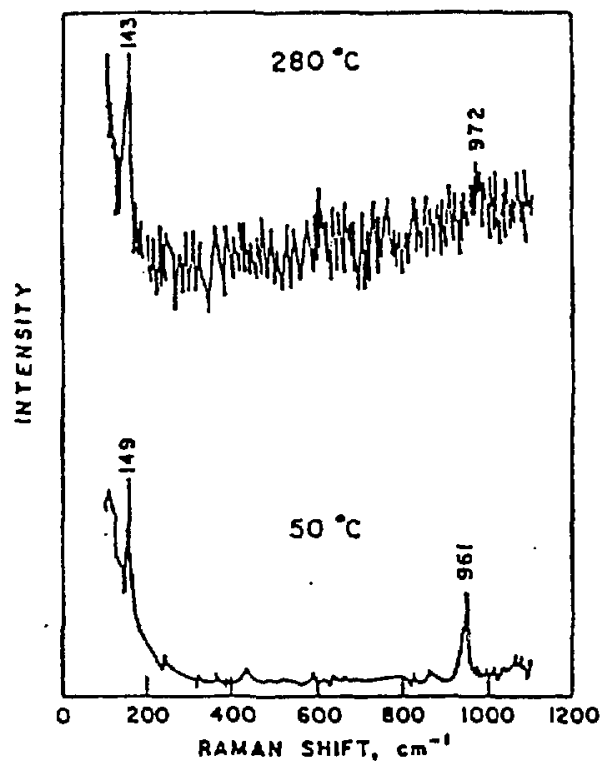

Figure 18. In-situ Raman spectra of corrosion films on $\mathrm{Pb}$ formed at open circuit.

Raman spectrum showed bands due to $\mathrm{SO}_{4}=$ vibrations, as well as one at $147 \mathrm{~cm}^{-1}$, which we attributed to $\mathrm{Pb}-0$ stretching. X-ray diffraction study of corrosion films scraped of the electrode surface indicated that the film consisted of the phase $3 \mathrm{PbO} \bullet \mathrm{PbSO}_{4} \cdot \mathrm{H}_{2} \mathrm{O}$ (or $\mathrm{Pb}_{4} \mathrm{O}_{3} \mathrm{SO}_{4} \bullet \mathrm{H}_{2} \mathrm{O}$ ). This film persisted up to about $110^{\circ} \mathrm{C}$. Above this temperature we found the phase $\mathrm{PbO}^{-\mathrm{PbSO}_{4}}$ (or $\mathrm{Pb}_{2} \mathrm{OSO}_{4}$ ) to predominate as exemplified by the bands at 143 and $972 \mathrm{~cm}^{-1}$ (Fig. 18).

Following successful demonstration of the operation of the HTHP facility, a study was subsequently conducted on the corrosion and passivation behavior of $\mathrm{Ni}$, an important component of stainless steel and other alloys used in reactor coolant systems. Fig. 19 shows cyclic voltammograms if $\mathrm{Ni}$ in $7 \times 10^{-4} \mathrm{M} \mathrm{Na}_{2} \mathrm{SO}_{4}$ solution as a function of temperature. Both primary (A) and secondary (B) passivation peaks are clearly evident at temperatures below $120^{\circ} \mathrm{C}$. Passivity breaks down above this temperature and the metal actively corrodes. The hysteresis in the current-potential curve above $200^{\circ} \mathrm{C}$ is interpreted to indicate the occurrence of pitting corrosion. Fig. 20 shows in-situ Raman spectra obtained by potentiostating the specimen in the secondary passivation region (about $0.55 \mathrm{~V}$ vs $\mathrm{Ag} / \mathrm{Ag}_{2} \mathrm{SO}_{4}$ ). The spectra observed correspond to that of "hydrous $\mathrm{NiO}_{2}$ " as we have shown in previous works. 13,33 


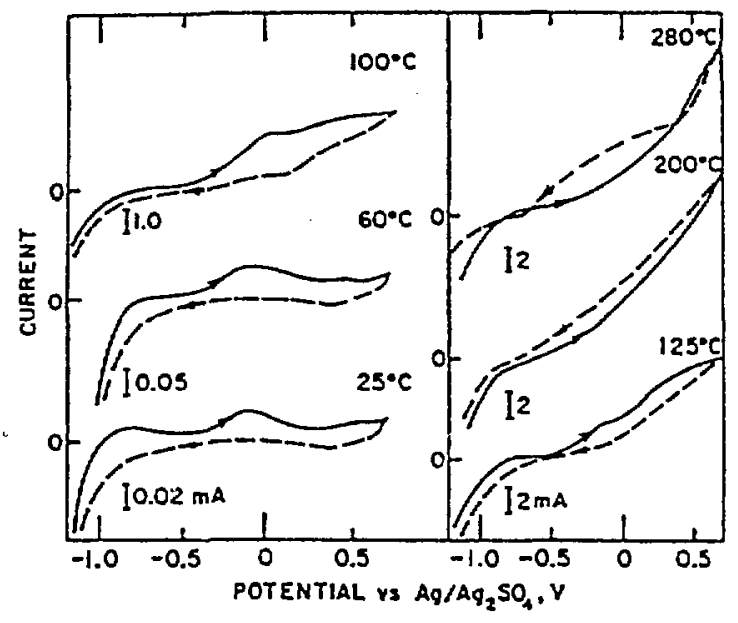

Figure 19. Cyclic voltammograms of $\mathrm{Ni}$ in $7 \times 10^{-4} \mathrm{M} \mathrm{Na}_{2} \mathrm{SO}_{4}$ as a function of temperature. Scan rate $=10 \mathrm{mV} / \mathrm{sec}$.

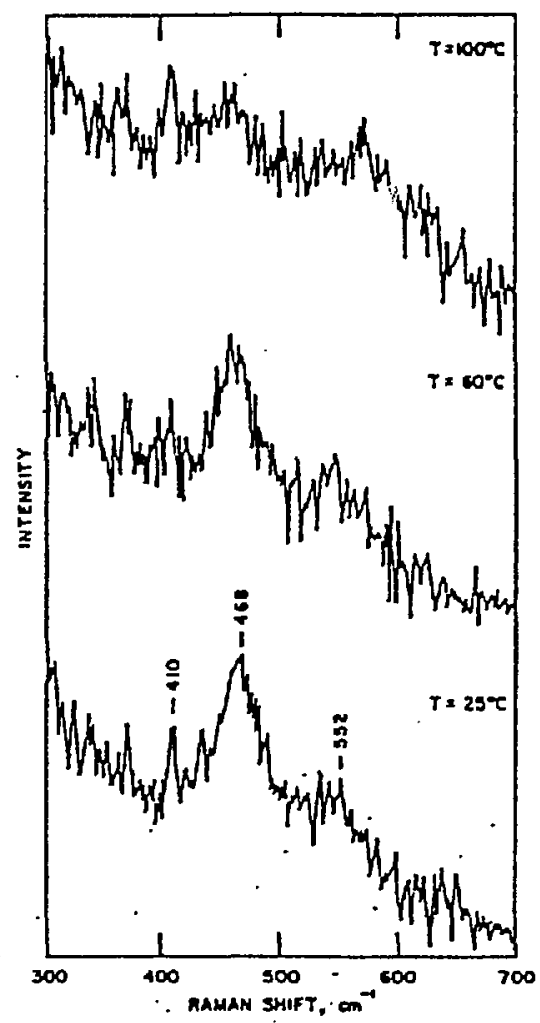

Figure 20. In-situ Raman spectra of secondary passive film on $\mathrm{Ni}$ in 7 $x 10^{-4} \mathrm{M} \mathrm{Na}_{2} \mathrm{SO}_{4}$ at various temperatures.

The film thickness is estimated to be about 100 to $200 \AA$. Attempts to obtain a spectrum of the film in the primary passivation region were 
not successful, probably because of the thinness of the film and its low Raman scattering cross-section.

We have demonstrated that it is possible to fruitfully undertake in-situ laser Raman spectro-electrochemical investigations of corrosion and passivation phenomena on metals in aqueous environments at high temperature and pressure. It is possible to extend such measurements to the critical point of water $\left(374^{\circ} \mathrm{C}\right)$ or even to supercritical conditions by using appropriate seals. The cell could be modified slightly for UV-visible reflection spectroscopy. Moreover, by replacing the sapphire window $\left(S_{2}\right)$ with a metal disc counter electrode, a more uniform current distribution could be achieved in purely electrode-kinetic measurements using fast transient techniques. The working electrode must also be modified accordingly for such studies.

\subsection{Applications to Studies in Electrocatalysis}

Several works have appeared in the literature on LRS investigations to elucidate the processes involved in electrocatalysis. Of great interest, in particular, is the use of transition metal macrocyclic compounds such as metallated phthalocyanines and porphyrins for the catalyzed electrochemical reduction of oxygen, $65,66,67$ hydrogen, 68 and carbon dioxide, 69,70 and of nitrite (to ammonia). 71 In view of space limitation, we will confine our discussions to the first application. This lecture will also serve as a cursory review of recent literature on the subject.

We digress briefly on the electrochemistry of oxygen reduction. The literature on this subject is very extensive; ${ }^{65}$ the understanding of this reaction is of great importance in such applications as fuel cells and corrosion, because it is often the rate controlling process in such systems. The reaction under consideration is thought to proceed in two parallel paths, ${ }^{65} i . e .$, for example in acid solutions:

1) The "peroxide" mechanism

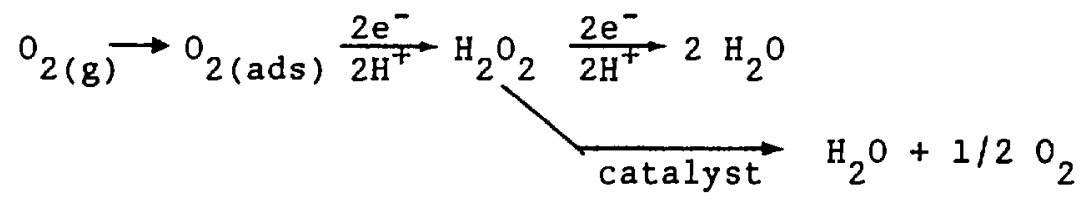

2) Direct 4-electron mechanism

$$
\mathrm{O}_{2(\mathrm{~g})} \rightarrow \mathrm{O}_{2(\mathrm{ads})} \frac{4 \mathrm{e}^{-}}{4 \mathrm{H}^{+}} 2 \mathrm{H}_{2} \mathrm{O}
$$

The first mechanism involves the production of peroxide which can be reduced further to $\mathrm{H}_{2} \mathrm{O}$ or can be decomposed catalytically to form $\mathrm{O}_{2}$ and $\mathrm{H}_{2} \mathrm{O}$. This pathway appears to predominate on such electrode surfaces as graphite, gold, transition metal oxides, and some metal macro- 
cyclic compounds like cobalt tetrasulfonated phthalocyanine. Direct 4electron reduction appears to proceed on electrodes like platinum, palladium, silver, tetrasulfonated iron phthalocyanine and a cobalt face-to-face porphyrin. 66

It is evident that establishment of the proper mechanism for oxygen reduction depends critically on the detection and identification of the intermediates formed; structural transformations that the catalysts undergo are also of utmost importance.

\subsection{Electrocatalysis by Transition Metal Macrocyclic Compounds}

The $\mathrm{O}_{2}$ reduction reactions (1) and (2) proceed at very slow rates under ordinary conditions so that it is necessary to employ a catalyst in practical applications. Transition metal macrocyclic compounds appear to be the most promising at present and have been studied extensively since they were first discovered by Jasinski. ${ }^{74}$ Different structural modifications, e.g., phthalocyanines, porphyrins, tetraazaannulenes, cyclic amines, etc. have been tested fur catalytic activity.

The literature on electrochemical studies using macrocyclics is rather extensive and no attempt will be made here to review it completely. The interested reader can refer to an earlier review by Jahnke, Schönborn, and Zimmerman. 75 We confine ourselves to studies using metalphthalocyanines and porphyrins. Yeager and his group 62,63 at Case Western Reserve University in particular have made significant contributions to the advancement of the field. They have characterized the electrochemical and spectroscopic properties of phthalocyanines and porphyrins both as thick films and adsorbed monolayers on carbon and metal substrates. They established that cobalt tetrasulfonated phthalocyanine adsorbed on graphite surfaces promoted $\mathrm{O}_{2}$ reduction via a 2electron process with the formation of peroxide; iron tetrasulfonated phthalocyanine allowed a direct 4-electron transfer to $\mathrm{H}_{2} \mathrm{O}$. Van Veen 72 in the Netherlands and Savy et al. 73 in France have likewise conducted detailed studies of phthalocyanine and porphyrin films supported on carbon. They investigated the effect of the central metal atom, electrolyte, and catalyst pretreatment on activity and sought correlations between the structure of the macrocycle and catalytic activity, as well as stability. Van Veen 72 established the order of activity among the phthalocyanines in both acidic and alkaline electrolyte to be Fe> Con $\mathrm{Ru}>\mathrm{Pd} \simeq \mathrm{Pt}>\mathrm{Zn}$. He also confirmed that heat treatment of the macrocycles in $\mathrm{N}_{2}$ or Ar atmosphere at temperatures up to $800^{\circ} \mathrm{C}$ enhanced the stability and activity of carbon-supported cobalt phthalocyanine (CoPc) and iron phthalocyanine $(\mathrm{FePc})$. This effect was discovered earlier by Bagotzky ${ }^{76}$ and his co-workers in the USSR.

Savy, et al. 73 found that polymeric iron phthalocyanines were more active catalytically than the monomeric form. They pointed out the importance of the electronic state of the central metal atom in determining activity and concluded from $x$-ray, optical, and ESCA measurements, that the active form of the iron ion in FePc has a high spin, $\mathrm{Fe}^{+3}$ configuration. More recently, Savy et al. 77 carried out UV-visible reflectance and electroreflectance measurements in conjunction with voltammetric and capacitance studies on vacuum deposited and adsorbed 
metal phthalocyanines on glassy carbon and Au electrodes. They found that the catalytic activity of FePc is related to the occurrence of a two-metal-centered redox process in the potential range between oxidation and reduction of the phthalocyanine ligand. They claimed that the formation of $\mu$-oxo and $\mu$-peroxo bridges between two iron centers is essential for catalytic activity.

Van der Putten et al. 67 likewise studied the electrochemical behavior of FePc, CoPc, and cobalt tetraazannulene (CoTAA) irreversibly adsorbed on pyrolitic graphite as a function of $\mathrm{pH}$ using cyclic voltammetry and rotating disc electrode techniques. They measured the redox potentials of the macrocycles as a function of $\mathrm{pH}$ and studied their behavior towards $\mathrm{O}_{2}$ reduction. They found a clear correlation between the redox potential of the central metal atom and the $\mathrm{O}_{2}$ reduction behavior at low $\mathrm{pH}$. Thus for CoTAA with a redox potential of $470 \mathrm{mV}$ more positive than $\mathrm{CoPc}$, the half wave potential, $E_{1 / 2}$, for $\mathrm{O}_{2}$ reduction was about $400 \mathrm{mV}$ more positive than $E_{1 / 2}$ for CoPc, i.e., CoTAA was more catalytically active than CoPc.

Van der Brink et al. 80 studied extensively the kinetics of $\mathrm{O}_{2}$ reduction on thick films of cobalt and iron phthalocyanine. They employed such techniques as cyclic voltammetry and rotating disc (with ring) to determine the rate constants for $\mathrm{O}_{2}$ reduction; they further used $A C$ impedance and ellipsometry to characterize the state of the electrocatalytic surface. They proposed a redox mechanism for the electrocatalysis of the $\mathrm{O}_{2}$ reduction reaction. The reduction kinetics on CoPc was found to be different from that of FePc. The stable reaction product at low cathodic overpotentials on $\mathrm{CoPc}$ was $\mathrm{H}_{2} \mathrm{O}_{2}$; only at more negative potentials does further reduction to $\mathrm{H}_{2} \mathrm{O}$ occur. No direct reduction of $\mathrm{O}_{2}$ to $\mathrm{H}_{2} \mathrm{O}_{2}$ was found over the entire potential range investigated. No $0-0$ bond rupture occurred in the formation of $\mathrm{H}_{2} \mathrm{O}_{2}$. In the case of $\mathrm{FePc}$, reduction of $\mathrm{O}_{2}$ in alkaline media proceeded directly to $\mathrm{OH}^{-}$, with $\mathrm{HO}^{-2}$ formation occurring as well only in a very narrow potential region. $\mathrm{HO}^{-2}$ was either reduced to $\mathrm{OH}^{-}$or decomposed chemically on FePc electrodes. On the scheme of redox catalysis, $\mathrm{O}_{2}$ is adsorbed on the CoPc electrocatalyst at the site of the central metal atom which results in a partial electron transfer to the $\mathrm{O}_{2}$. Electron transfer to the $\mathrm{COPC}-\mathrm{O}_{2}$ complex leads to the production of $\mathrm{HO}_{2}$. In the case of $\mathrm{FePc}$, the $\mathrm{Fe}$ (III) $\mathrm{PC}-\mathrm{O}_{2}^{-}$is reduced in a series of fast electron transfers to produce $\mathrm{OH}^{-}$and $\mathrm{HO}_{2}$.

A number of electrochemical studies have also been carried out by Kuwana and others 78,79 on water soluble porphyrins and their derivatives in solution or adsorbed on carbon electrodes. It appears that these compounds catalyze the reduction of $\mathrm{O}_{2}$ only to the peroxide stage via an electrochemical-chemical (EC) mechanism. As an example, for iron tetra-4-N-methylpyridy1-porphyrin pentachloride, i.e. $\mathrm{Fe}$ (III) $\mathrm{TMP}^{5+} \mathrm{Cl}^{-}$, we have the reactions

$$
\begin{aligned}
& \mathrm{Fe}\left(\text { III) } \mathrm{TMP}^{+5}+\mathrm{e} \longrightarrow \mathrm{Fe} \text { (II) } \mathrm{TMP}^{+4}\right. \\
& \mathrm{Fe}\left(\text { II) } \mathrm{TMP}^{+4}+1 / 2 \mathrm{O}_{2}+\mathrm{H}^{+} \stackrel{\mathrm{k}}{\longrightarrow} \mathrm{Fe}\left(\text { III) } \mathrm{TMP}^{+5}+1 / 2 \mathrm{H}_{2} \mathrm{O}_{2} .\right.\right.
\end{aligned}
$$


Anson and his group 81,82 have also undertaken extensive investigations on both dissolved and adsorbed metal porphyrins as $\mathrm{O}_{2}$ reduction electrocatalysts. They studied $\mathrm{O}_{2}$ reduction at graphite electrodes coated with thick layers of iron (III) protoporphyrin IX (FePP IX), iron (III) meso-tetraphenylporphine (FeTPP), and iron (III) meso-tetra (3-pyridy 1 ) porphine (FeTPyP). Using rotating disk and ring-disk techniques, they showed that the first two compounds were effective catalysts for the reduction of $\mathrm{O}_{2}$ and $\mathrm{H}_{2} \mathrm{O}_{2}$ to $\mathrm{H}_{2} \mathrm{O}$ over a wide $\mathrm{pH}$ range. They also proposed a redox-type mechanism which involved an initial reaction between the reduced form of the porphyrin and the substrate. The product of the $\mathrm{O}_{2}$ reduction undergoes further rapid reaction at the electrode. Only the outer portions of the catalyst coating participated in the catalysis.

Collman and his group together with Anson, 66,82 synthesized dicobalt porphyrin dimers (so called face-to-face porphyrins) and found them to have high catalytic activity towards the reduction of oxygen to water without producing significant amounts of hydrogen peroxide. This suggests that $\mathrm{O}_{2}$ bridging of two-cobalt centers facilitates cleavage of the $0-0$ bond and thus direct 4 e-reduction to $\mathrm{H}_{2} \mathrm{O}$. The catalytic activity of the porphyrin dimers investigated by Collman et al. 66,82 was found to be a sensitive function of the geometry, the type of metal centers and their distance of separation. The mechanism of reduction is again believed to be initially a $2 \mathrm{e}^{-}$transfer resulting in the reduction of two Co(II), followed by reoxidation of these two centers and then bridging by $\mathrm{O}_{2}$; finally, a further $2 \mathrm{e}^{-}$reduction and protonation occurs with the formation of water molecules as shown below.
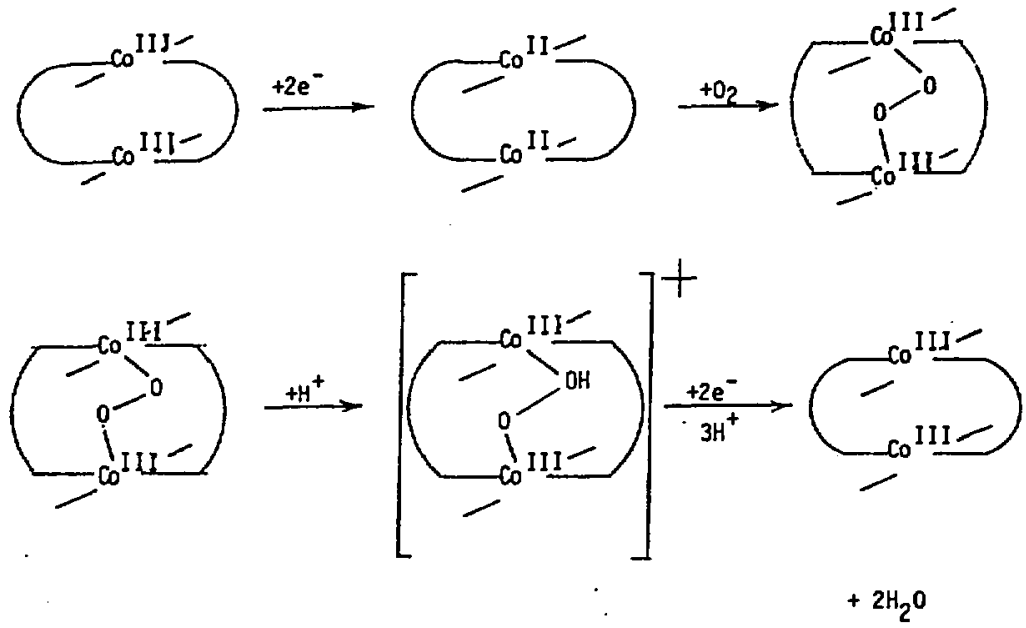

We have also studied the reduction of $\mathrm{O}_{2}$ on thick FePc films using cyclic voltammetry and rotating disk (with ring) techniques. ${ }^{83}$ We found that the loss of catalytic activity of the film on cycling and with time is due to the production of $\mathrm{H}_{2} \mathrm{O}_{2}$ which results in oxidative 
dissolution of the catalyst. Heat treatment of carbon-supported phthalocyanines at temperatures up to $900^{\circ} \mathrm{C}$ as was found by Bagotzky 76 apparently increases the stability of the catalyst most probably by producing modified structures which are more resistant to oxidative dissolution.

There are many other electrochemical studies worthy of note, but this short lecture will not allow reviewing all of them; the author apologizes to those whose work has been inadvertently omitted. This brief survey is meant only to be an overview of the field and the interested reader can refer further to the many other original references cited in the papers quoted herein.

\subsection{Raman Spectroscopy of Adsorbed Macrocycles}

Two types of surface films of metal phthalocyanines and porphyrines have been studied: 1) adsorbed macrocycles on electrodes at monolayer or near-monolayer thickness, 84,85 and 2) films from $100 \AA$ to a few microns thick. $86-88$ We consider first some of the investigations on adsorbed layers. 90

Kötz and Yeager ${ }^{83 b}$ first obtained the in situ Raman spectra of cobalt tetrasulfonated phthalocyanine (CoTSPC) adsorbed on a silver electrode in $0.05 \mathrm{M} \mathrm{H}_{2} \mathrm{SO}_{4}$ solution. They found that the intensity of the Raman bands increased linearly with the amount of charge transferred during the electrochemical activation of the $\mathrm{Ag}$. The spectra of the adsorbed CoTSPC was very much like that of dissolved CoTSPC, indicating that the molecule interacted only weakly with the surface. They measured the variation in intensity of a number of bands with electrode potential, and found that the intensity of four Raman bands was modified by the presence of $\mathrm{O}_{2}$ in the solution; i.e., bands at 1609 and $1597 \mathrm{~cm}^{-1}$ are enhanced significantly, a band at $694 \mathrm{~cm}^{-1}$ is diminished in intensity while a new band appears at $1153 \mathrm{~cm}^{-1}$ when oxygen is present. They found a surprising similarity between changes in the Raman spectra of the solution species due to $\mathrm{O}_{2}$ saturation and changes in the surface vibrational spectra due to the application of negative potentials. They also observed significant change in spectra at potentials in the hydrogen evolution region which indicate a major alteration in the structure of the adsorbed species.

Simic-Glavaski et al. 84 have characterized extensively the spectroscopic behavior of the tetrasulfonated forms of metal free phthalocyanine ( $\mathrm{H}_{2} \mathrm{TSPC}$ ), iron phthalocyanine (FeTSPC), and cobalt phthalocyanine (CoTSPC). All molecules were adsorbed on Ag electrodes and were studied in acidic, basic, and neutral solutions. They also studied the solution phase species as well as the effect of $\mathrm{O}_{2}$ on the system using UV-visible and Raman spectroscopy. The UV-Visible absorption spectra of $\mathrm{H}_{2} \mathrm{TSPC}$ and CoTSPC showed bands at about $335 \mathrm{~nm}($ Soret, $\gamma$ or $\mathrm{B}(0,0))$, $630 \mathrm{~nm}(\beta$ or $Q(1,0))$ and $660 \mathrm{~nm}(\alpha$ or $Q(0,0))$. These bands are thought to be due to $\pi \rightarrow \pi^{*}$ transitions within the delocalized phthalocyanine ring system. Marked changes in the absorption spectra for $\mathrm{H}_{2}$ TSPc were observed when the $\mathrm{pH}$ was varied. The $Q$ band splitting observed in neutral and alkaline solutions disappeared in acid solution due to protonation which changed the molecular symmetry from $D_{2 h}$ to $D_{4 h}$. The 
effect of $\mathrm{pH}$ on the absorption spectra of CoTSPc was not as marked, however, variation in concentration of the macrocycle resulted in higher intensity of the $Q(0,0)$ band and a shift toward longer wavelength by as much as $20 \mathrm{~nm}$ as the CoTSPc concentration was lowered. A shift in the $Q(0,0)$ band was also found upon $\mathrm{O}_{2}$ saturation of acid and alkaline solutions. This shift is believed to be due to the formation of an $\mathrm{O}_{2}$ adduct with the macrocycle.

The Raman spectrum of adsorbed phthalocyanine was found to be very much like that in the solid and in solution; this suggests a rather weak interaction between the macrocycle and the $\mathrm{Ag}$ electrode, i.e., physisorption rather than chemisorption. The cyclic voltammetry curves showed two peaks in the anodic and cathodic cycles for $\mathrm{H}_{2}$ TSPC, CoTSPC and FeTSPC which led the authors to conclinde that these correspond to the oxidation and reduction of the TSPC ligand rather than the central metal atom. Raman spectra were recorded over the entire pH range of 113. The bands did not show any shift in frequency as a function of $\mathrm{pH}$ but the intensities showed significant change when the electrode potential was altered. The $612 \mathrm{~cm}^{-1}$ band for FeTSPC, $763 \mathrm{~cm}^{-1}$ for CoTSPC, and $506 \mathrm{~cm}^{-1}$ for $\mathrm{H}_{2}$ TSPc were found to shift in frequency as a function of potential. The $612 \mathrm{~cm}^{-1}$ band for FeTSPc showed two characteristic inflection points in the plot of frequency shift vs potential which appeared to coincide with the two oxidation peaks in the cyclic voltammogram. The authors followed the change in intensity of selected bands as the voltage was scanned and then constructed what they called Voltage-Raman (VR) plots. The curves often exhibited a maximum at certain voltages which shift as the $\mathrm{pH}$ of the solution was varied. The most noticeable change in the Raman band intensities occurred in potential regions of the oxidation-reduction peaks; the intensity of a Raman band appeared to be a function of the oxidation state of the adsorbed phthalocyanine.

Substantial changes were also observed in the Raman intensities of the adsorbed macrocycles upon oxygenation of the solution. The maxima in the VR curves were found to shift to more negative potentials in the oxygenated solution compared to the deoxygenated ones. This potential shift paralleled a similar shift of the VR maxima with $\mathrm{pH}$ which was explained on the basis of a shift in the redox potential of the $\mathrm{O}_{2}$ adduct with $\mathrm{pH}$.

We have also obtained the Raman spectra of iron phthalocyanine (FePC) adsorbed on $\mathrm{Cu}$ and $\mathrm{Au}$ electrodes $85 \mathrm{a}$ in $0.05 \mathrm{M} \mathrm{H}_{2} \mathrm{SO}_{4}$. Adsorption was originally carried out by immersing the metal electrode in a dilute solution of the macrocycle in pyridine as solvent. Transfer of the electrode to the aqueous solution resulted in the appearance of a band at $1529 \mathrm{~cm}^{-1}$ in situ which was interpreted as being due to interaction of the FePc with water molecules at the bridging nitrogen positions. A decrease in intensity and broadening of some vibrational bands was observed on increasing cathodic polarization; these were attributed to a lifting of the degeneracy of some vibrational modes due to a change in symmetry of the adsorbed molecules brought about by polarization induced by the double-layer field.

We have likewise studied the surface Raman scattering and electrochemistry of iron protoporphyrin IX chloride, Fe(III)PPCI, adsorbed on 
a silver electrode in sodium borate solution. $85 \mathrm{~b}$ Modest catalysis of the $\mathrm{O}_{2}$ reduction reaction was found in the presence of $\mathrm{Fe}$ (III)PPCl. It was possible to discriminate between the reduction of Fe(III) occurring in the solution and that on the electrode surface. The Raman data indicated that an intermediate-spin, 4-coordinate iron (III) porphyrin (Fe(III)PP) was adsorbed on the electrode and a high-spin, more highly coordinated iron (II) species (Fe(II)PP) existed in the solution.

\subsection{Investigations of Thick Films}

Electrochemical and spectroscopic characterization of fairly thick phthalocyanine films had been carried out in a number of laboratories. $86-93$

Aroca and his co-workers 96,97 studied the Raman spectra of a variety of phthalocyanine films supported on glass substrates. They gave a description of the various modes of vibration of these macrocycles and showed some correlations in the vibrational properties of the series $\mathrm{Mg}, \mathrm{Cu}$ and $\mathrm{Zn}$ phthalocyanines. They also used polarization Raman techniques (i.e., a study of the scattering of polarized light) to probe the molecular orientation of submicron films of phthalocyanines. They found a splitting of certain vibrational modes of the molecules which is due to the crystalline field of the film. This correlation field or "Davydov splitting" could provide unique and useful information about the crystalline nature of organic thin films.

Kahl et al. 88 studied the reversible oridation and reduction of magnesium phthalocyanine films (1000-2000 A thick) supported on a Au substrate in aqueous solutions of $\mathrm{NaCl}, \mathrm{NaNO}_{3}$ and potassium hydrogen phthalate (KHP). They observed changes in the Raman spectra of MgPc during oxidation and reduction which they associated with the vibrational modes of the Pc rings; these led them to the conclusion that the oxidation occured at the Pc ligand instead of the central metal atom. They also demonstrated that the anions from the solution moved into and out of the organic film during the oxidation and reduction processes as would be necessary for proper charge compensation. Their results also showed that anion size determined the rate of oxidation, i.e., smaller anions $\left(\mathrm{Cl}^{-}, \mathrm{ClO}_{4}{ }^{-}\right)$allowed rapid rates while larger ones, e.g. the biphthalate anion, permitted only limited or "surface" oxidation. $\mathrm{SO}_{4}=\mathrm{HPO}_{4}=$ and $\mathrm{SiF}_{6}=$ did not allow oxidation of the MgPc at potentials up to $0.9 \mathrm{~V}$ vs SCE.

We have also studied the electrochemical and laser Raman spectroscopic behavior of thick iron phthalocyanine films supported on carbon. 90 We found that different methods of preparing the film resulted in different polymorphic forms of FePC on the surface, which in turn yielded varying catalytic activity for $\mathrm{O}_{2}$ reduction. The films were found to deactivate during voltammetric cycling; we subsequently showed this to be due to the anodic dissolution of the film. LRS indicated coordination of the $\mathrm{FePc}$ with $\mathrm{H}_{2} \mathrm{O}$ molecules in the solution. The vibrational spectra, however, did not show any significant changes in the potential range from 0.4 to $-0.9 \mathrm{~V}$ vs $\mathrm{Hg} / \mathrm{Hg}_{2} \mathrm{SO}_{4}$. 


\subsection{Theoretical Analysis of Vibrational Spectra}

The successful interpretation of Raman spectral data to obtain information on molecular structure depends acutely on a theoretical model of the atomic assembly comprising the system and the force of the interactions between atoms. The normal modes of vibration of a molecular system consisting of $\mathrm{N}$ atoms can be determined by a procedure developed by Wilson and co-workers that has come to be known as the FG Matrix method $^{98}$ of normal coordinate analysis. Details of this theoretical method appear in a number of publications 18,98 and need not be elaborated here.

Normal coordinate treatments of the vibrational modes of metalloporphyrins have been performed by a number of workers.99-101 Jennings et al. 102 have made assignments of the vibrational modes of $\mathrm{Mg}, \mathrm{Cu}$ and Zn phthalocyanines. Using normal coordinate analysis we have assigned the planar modes of vibration of iron phthalocyanine.103 Good agreement was obtained between calculated and observed frequencies using an adjusted valence force field (AVFF) and incorporating empirical correlations for related types of force constants. We found the assignments of the normal modes of vibration to be consistent with other available experimental and theoretical information for phthalocyanine complexes and related metalloporphines. However, the extensive mixing of the internal coordinates within the calculated normal modes showed clearly that assignments of specific vibrational frequencies to individual internal coordinates is generally not justified. The vibrational kinematics appear to involve concerted motions of the various interior and exterior ring systems.

\subsection{LIMITATIONS OF THE RAMAN SPECTROSCOPIC TECHNIQUE}

While we have highlighted the advantages of the LRS technique for studies in corrosion and electrocatalysis, it is also important to point out the limitations. There is plenty of room for improvement in detection sensitivity to enable the study of corrosion and passivation films at near monolayer levels. This is inherently difficult for oxide or hydroxide films because the corrosion process itself causes roughening of the metal surface and thus increases the background of diffuse scattered light. The low frequency of the metal-oxygen vibration (generally less than $1000 \mathrm{~cm}^{-1}$ and hence closer to the Raleigh line) compounds the problem of picking up a weak signal from a high background. Metal oxides have, morever, also relatively low cross sections for Raman scattering.

Black and dark colored samples generally have a high absorption coefficient for visible light and hence exhibit weak Raman scattering. Sample heating by the incident laser can be minimized by spinning the sample or through the use of other related techniques. It is also very important experimentally to check that the Raman spectra obtained are not due to the decomposition products of photoreactive samples. One way of doing this is to obtain spectra at different laser powers and to use the lowest power possible on the sample. 
The laser beam used to probe the sample can cause other structural and compositional changes on the sample, e.g. the drying of normally hydrous surface films, sample decomposition, etc. The need to determine film compositions in-situ cannot be overemphasized and spectra obtained ex-situ should always be interpreted with caution. $38 \mathrm{c}, 42$

\subsection{FUTURE OUTLOOK}

We have given here a survey of the applications of Raman spectroscopy in conjunction with electrochemical studies in aqueous corrosion and electrocatalysis. The survey is by no means complete and will undoubtedly be rather quickly outdated. The author anticipates more and more use of the technique in electrochemistry. New developments in detector technology and advances in other aspects of Raman instrumentation, such as better monochromators and filters, will enhance sensitivity to the region of monolayer and submonolayer quantities of electrocatalysts and corrosion films. Such capability has already been demonstrated for cyanopyridine on Rh. 104 The phenomenon of SERS will continue to be applied to appropriate systems using $\mathrm{Au}, \mathrm{Ag}$, and $\mathrm{Cu}$ electrodes. The development of Fourier transform Raman spectrometers should bring about significant reduction in the cost of Raman facilities and hence encourage wider use of the technique. The combination of FTIR and Raman spectroscopy in a single instrument is becoming popular and would represent a powerful capability for electrochemical and surface science laboratories.

\subsection{Acknowledgement}

The author acknowledges support of his research by the U.S. Department of Energy, Office of Basic Energy Sciences, Division of Materials Science, under contract W-31-109-Eng-38. He also thanks his colleagues and students, among them $W$. Ruther, J. J. McMahon, S. Xu, X. Feng, W. Paden, C. Rios, W. Walczak, T. Tipton, N. Camillone III, L. PenaCordova, R. Grubbs, and J. Solis-Fernandez, for their help in the conduct of laboratory experiments. The continued encouragement of $\mathrm{V}$. A. Maroni and D. M. Gruen at Argonne National Laboratory is gratefully acknowledged. 


\subsection{REFERENCES}

1a. M. C. Tobin, Laser Raman Spectroscopy, Wiley Interscience, New York (1971).

b. P. R. Carey, Biochemical Applications of Raman and Resonance Raman Spectroscopies, Academic Press, NY (1982).

2a. M. Fleischmann, P. J. Hendra and A. J. McQuillan, J. Chem. Soc. Chem. Communications (1973), 80 .

b. A. Campion, Vibrational Spectroscopy of Molecules on Surfaces,

J. T. Yates Jr. and T. E. Madey, editors, Plenum Press, NY, 1987. p. 345 .

c. D. K. Veirs, V. K. F. Chia, and G. M. Rosenblatt, Applied Optics, 26,3530 (1987).

3. R. Kötz and E. Yeager, J. Electroanal. Chem. 111, 105 (1980).

4. J. DeSilvestro and M. J. Weaver, J. Electroana1. Chem. 209, 377 $(1986)$.

5a. R. J. Thibeau, C. W. Brown, A. Z. Goldfarb and R. H Heidersbach, J. Electrochem. Soc. 127, 37 (1980).

b. E. S. Reid, R. P Cooney, P. J. Hendra and M. Fleischman, J. Electroanal. Chem. 80, 405 (1977).

6. R. Varma, C. A. Melendres and N. P. Yao, J. Electrochem. Soc. 207, 1416 (1980).

7. C. A. Melendres, S. Xu and B. Tani, J. Electroanal. Chem. 162, 343 (1984).

8. J. C. Hamilton, J. C. Farmer, and R. J. Anderson, J. Electrochem. Soc. 133, 739 (1986).

9. C. A. Melendres and S. Xu, J. Electrochem. Soc. 131, 2239 (1984).

10. J. Dünnwald, R. Lossy and A. Otto in Passivity of Metals and Semiconductors, M. Froment (editor), Elsevier Science Publishers, Amsterdam (1983) p. 107.

11. M. Froelicher, A. Hugot Le-Goff, C. Pallotta, et al. - ibid. p. 101.

12. I.C.G. Thanos, Electrochimica Acta 31, 811 (1986).

13. K. Carr, S. Baer and C. A. Melendres, Corrosion, 42, 307 (1986). 
14. J. DeSilvestro, D. A. Corrigan and M. J. Weaver, J. Electrochem. Soc. 35,885 (1988).

15. R. J. Thibeau, C. W. Brown, et. al., J. Electrochem. Soc. 127, 1913 (1980).

16. J. J. McMahon, W. Ruther, and C. A. Melendres, J. Electrochem. Soc. 135, 557 (1988).

17. M. Pourbaix "Atlas D'equilibres Electrochimiques", GauthiersVillars, Paris (1963) p. 489.

18. K. Nakamoto, Infrared and Raman Spectra of Inorganic and Coordination Compounds, Third Edition, John Wiley, New York (1978).

19. W. G. Fateley, F. R. Dollish, et.al Infrared and Raman Selection Rules for Molecular and Lattice Vibrations: The Correlation Method, Wiley Interscience, New York (1972).

20. J. Burbank, A. C. Simon and E. Willihnganz in Advances in Electrochem. and Electrochem. Enginnering, edited by $C$. W. Tobias and P. Delahay, vol. 8, (1971) p. 157.

21. R. K. Chang and T. E. Furtak, editors, Surface Enhanced Raman Scattering, Plenum Press, NY (1982).

22. P. Gao, M. L. Patterson, et al., Langmuir, 1, 173 (1985).

23. J. DeSilvestro and M. J. Weaver, J. Electroanal Chem. 209, 377 (1986).

24. B. E. Conway and H. Angerstein-Kozlowska, NBS Publication 455, 107 (1976).

25. N. Sato and T. Ohtsuka, J. Electrochem. Soc. 125, 1735 (1978).

26. K. Kudo, N. Sato and $T$. Ohtsuka in "Passivity of Metals", R. P. Frankenthal and J. Kruger, editors, the Electrochem. Soc. monograph series, Princeton, New Jersey (1978) p. 918.

27. H. Leidheiser Jr, G. W. Simmons and E. Kellerman, J. Electrochem. Soc. 120,1516 (1973).

28. G. W. Simmons, E. Kellerman and H. Leidheiser Jr, J. Electrochem. Soc. $123,1276(1976)$.

29. P. Delichere, A. Hugot Le-Goff and N. Yu "Proceedings of the Tenth International Conference on Raman Spectroscopy, W. L. Peticolas and B. Hudson, editors, University of Oregon Press, Eugene, Oregon (1986) p. 5-45. 
30. J. DeSilvestro, D. A. Corrigan and M. J. Weaver, J. Phys. Chem. 90, 6408 (1986).

31. F. Hahn, B. Beden, J. J. Croissant and C. Lamy, Electrochimica Acta 31, 335 (1986).

32. K. Carr, S. Baer and C. A. Melendres, Corrosion 42, 307 (1986).

33. C. A. Melendres, W. Paden, B. Tani and W. Walczak, J. Electrochem. Soc. 134, 762 (1987).

34. D. A. Corrigan and S. L. Knight, J. Electrochem. Soc. 136, 613 (1989).

35. C. A. Melendres and B. S. Tani, J. Electrochem. Soc. 133, 1059 (1986).

36. G. Nazri, Ph.D. Thesis, Case Western Reserve University, 1981. (University Microfilms \$3267, Ann Arbor, Michigan).

37a. 0. Glemser and J. Einerhand, 2. Anorg. Chem. 261, 26 (1950; 2. Elektrochemie 54, 302 (1954).

b. R. W. Cairns and E. Ott, J. Amer. Chem. Soc. 55, 527 (1933); 55, 534 (1973).

C. P. Bro and D. Cogley, J. Electrochem. Soc. 113, 521 (1966).

d. K. Nakagawa, R. Konaka, and T. Nakata, J. Amer. Chem. Soc. 27, 1597 (1962).

38a. A. Hugot Le-Goff and C. Pallotta in Proceedings of the Tenth International Conference on Raman Spectroscopy, W. L. Peticolas and B. Hudson, editors, University of Oregon Press, Eugene, Oregon (1986) p. 6-16.

b. A. Hugot Le-Goff and C. Pallotta, J. Electrochem. Soc. 132, 2805 (1985).

c. A. Felske and W. J. Plieth, Electrochimica Acta, 34, 75 (1989).

39. R. J. Thibeau, C. W. Brown and R. H. Heidersbach, Applied Spectroscopy 32, 532 (1978).

40. J. T. Keiser, C. W. Brown and R. H. Heidersbach, Corrosion, 38, 352 (1982).

41. G. Nazri and E. Yeager, Extended Abstracts, Electrochem. Soc. Meeting, San Francisco, CA., May 8-13, 1983; Abstract No. 54. 
42. C. A. Melendres, N. Camillone III and T. Tipton, Electrochimica Acta., 34, 281 (1989).

43. J. T. Keiser, C. W. Brown and R. H. Heidersbach, Corrosion, 38, 357 (1982).

44. J. T. Keiser, C. W. Brown and R. H. Heidersbach, Proceedings of the Second International Conference on Environmental Degradation of Materials, Virginia Polytechnic Institute and state University, Blacksburg, VA, Sept. 22-23, 1981, p. 43.

45. D. J. Gardiner, M. Bowden and P. R. Graves, Phil. Trans. Roy. Soc. Lond. A320, 295 (2986).

46. R. L. Farrow, R. E. Benner, A. S. Nagelberg and P. L. Mattern, Thin Solid Films, 73, 353 (1980).

47. D. Thierry, D. Persson, C. Leygraf, et. a1., J. Electrochem. Soc. 132,305 (1985).

48. T. Ohtsuka, J. Guo and N. Sato, J. Electrochem. Soc. 133, 2473 (1986).

49. See for example, Proceedings of the Sixth European Symposium on Corrosion Inhibitors, Ferrara, Italy, Sept. 16-20, 1985, vols. I \& II.

50. G. H. Cartledge, Corrosion 18, 316t (1962).

51a. J. J. Kester, T. E. Furtak, and A. J. Bevolo, J. Electrochem. Soc., 129, 1716 (1982).

b. D. Thierry and C. Leygraf, J. Electrochem. Soc. 133, 2236 (1986).

52. B. H. Loo, Y, G. Lee and A. Etlage in Proceedings of the Ninth International Conference on Raman Spectroscopy, Tokyo, Japan, Aug. 27-Sept. 1, 1984, p. 538 .

53. B. H. Loo, Chem. Phys. Letters 89, 346 (1982).

54. J. Rubin, I. G. R. Gutz, O. Sala and W. J. Orville-Thomas, J. of Molecular Structure, 100, 571 (1983).

55. D. Thierry and C. Leygraf, J. Electrochem. Soc. 132, 1009 (1985).

56. M. Ohsawa and W. Süetaka, J. Electron Spec. and Related Phenomena 30,221 (1983).

57. C. A. Melendres, J. J. McMahon and W. Ruther, J. Electroanal. Chem. 208, 175 (1986). 
58. W. Ruther, J. J. McMahon and C. A. Melendres, in Surfaces, Inhibition and Passivation - Proceedings of an International Symposium, E. McCafferty and R. J. Brodd, editors, vol. 86-7, The Electrochem. Soc. Inc., Princeton, New Jersey (1986).

59. M. J. Danielson, Corrossion 35, 200 (1979).

60. M. Lepeintre, C. Mahieu and J. Monjou, C. R. Acad. Sci. Paris 261, 3389 (1965).

61. R. Heidersbach, C. Brown, R. Thibeau and A. Goldfarb, Technical Report No. 4, Contract No. N00014-76-C-0889, Office of Naval Research, Metallurgy Program - Code 471, Aug. 1978.

62. E. Yeager, in Proceedings of the Symposium on Electrode Materials and Processes for Energy Conversion and Storage, edited by J. D. McIntyre, S. Srinivasan and F. G. Will, The Electrochem. Soc. Inc., Princeton, NJ (1977), p. 149.

63. J. H. 2agal-Moya, Ph.D. Thesis, Case Western Reserve University (1978), University Microfilms, No. 7816494, Ann Arbor, MI, 48106.

64. B. Z. Nikolic, R. R. Adzic and E. Yeager, J. Electroanal. Chem. 103, 281 (1979).

65. M. Tarasevich, A. Sadkowski and E. B. Yeager in Comprehensive Treatise in Electrochemistry, B. E. Conway, J. O'M. Bockris, et al., editors, Plenum Press, NY (1983); vol. VII, P. 301.

66. J. P. Collman, P. Denisevich, P. Konai, M. Marrocco, C. Koval and F. C. Anson, J. Amer. Chem. Soc. 102, 6027 (1980).

67. A. Vander Putten, A. EIzing, W. Visscher and E. Barendrecht, J. Electroanal. Chem. 221, 95 (1987).

68. R. M. Kellett and T. G. Spiro, Inorg. Chem. 24, 2378 (1985).

69. S. Kapusta and N. Hackerman, J. Electrochem. Soc. 131, 1511 (1984).

70. D. Masheder and K. P. J. Williams, J. Raman Spec. 18, 387 (1987).

71. M. H. Barley, K. Takeuchi, W. R. Murphy Jr. and T. J. Meyer, J. Chem. Soc. Chem. Commun. 1985, 507.

72. J. A. R. Van Veen and C. Visser, Electrochimica Acta 24, 921 (1979).

73. M. Savy, C. Bernard and C. Magner, Electrochimica Acta 20, 383 (1975). 
74. R. Jasinski, J. Electrochem. Soc. 112, 526 (1965).

75. H. Jahnke, M. Schönborn and G. Zimmerman, Topics in Current Chemistry, 61, 133 (1976).

76. V. S. Bagotzky, M. R. Tarasevich, K. A. Radyushkina, et. al., J. Power Sources 2, $233(1977 / 78)$.

77. D. Van den Ham, C. Hinnen, G. Magner and M. Savy, J. Phys. Chem. 91, 4743 (1987).

78. T. Kuwana, M. Fujihira, K. Sunakawa and T. Osa, J. Electroanal. Chem. 88, 299 (1978).

79. N. Kobayashi, M. Fujihira, et al., J. Electroanal. Chem. 101, 269 (1979); 103, 427 (1979).

80. F. Van der Brink, W. Visscher and E. Barendrecht, J. Electroanal. Chem. 157, 283 (1983); 157, 305 (1983);172, 301 (1984);175, 279 (1984).

81. R. Durand Jr. and F. C. Anson, J. Electroanal. Chem. 143, 273 (1982).

82. J. P. Collman, M. Marrocco, P. Denisevich, C. Koval and F. C. Anson, J. Electroanal. Chem. 101, 117 (1979).

83a. C. A. Melendres and X. Feng. J. Electrochem. Soc. 130,811 (1983).

b. R. Kötz and E. Yeager, J. Electroanal. Chem. 113, 113 (1980).

84. B. Simic-Glawaski, S. Zecevic and E. Yeager, J. Electroanal. Chem. 150, 469 (1983); 194, 155 (1985); J. Raman Spectroscopy 14, 338 (1983); J. Physical Chem. 87, 4555 (1983); J.Amer. Chem. Soc., 107, 5625 (1985).

85a. C. A. Melendres, C. B. Rios, X. Feng and R. McMasters, J. of Physical Chem. 87, 3526 (1983).

b. J. J. McMahon, S. Baer, and C. A. Melendres, J. of Physical Chem., 90, 1572 (1986).

86. F. R. Fan and L. R. Faulkner, J. Amer. Chem. Soc. 101, 4779 (1979); H. Tachikawa and L. R. Faulkner, J. Amer. Chem. Soc. 100, 4379 (1978).

87. J. M. Green and L. R. Faulkner, J. Amer. Chem. Soc. 105, 2950 (1983). 
88. J. L. Kahl, L. R. Faulkner, K. Dwarakanath and H. Tachikawa, J. Amer. Chem. Soc. 108, 5434 (1986).

89. C. A. Melendres and X. Feng, J. Electrochem. Soc. 130, 811 (1983).

90. C. A. Melendres and F. A. Cafasso, J. Electrochem. Soc. 128, 755 (1981).

91. A. J. Appleby and M. Savy, in Proceedings of the Symposium on Electrode Materials and Processes for Energy Conversion and Storage, edited by J. D. E. McIntyre and S. Srinivasan, The Electrochem. Soc., Princeton, New Jersey, 77-6, 321 (1977).

92. M. Savy, C. Bernard and G. Magner, Electrochem. Acta. 20, 383.

93. C. Paliteiro, A. Hamnett, and J. B. Goodenough, J. of Electroanal. Chem., 249, 167 (1988).

94. D. Scherson, S. B. Yao, E. B. Yeager, et al., Applications of Surface Science, 10,325 (1982).

95. D. A. Scherson, S. B. Yao, E. B. Yeager, et al., J. Electroanal. Chem. 150, 535 (1983).

96. R. Aroca, C. Jennings, R. O. Loutfy and A. Hor, J. Phys, Chem. 90, $5255(1986)$.

97. C. Jennings, R. Aroca, A. Hor and R. O. Loutfy, J. Raman Spec. 15, 34 (1984).

98. E. B. Wilson Jr., J. C. Decius and P. C. Cross, Molecular Vibrations, McGraw Hill, NY (1955).

99. S. Sunder and H. J. Bernstein, J. Raman Spectroscopy, 5, 351 (1976).

100. H. Ogoshi, Y. Saito and K. Nakamoto, J. Chem. Phys. 57, 4194 (1972).

101. M. Abe, T. Kitagawa and Y. Kyogoku, J. Chem. Phys. 16, 4526 (1978).

102. C. Jennings, R. Aroca, A. M. Hor and R. O Loutfy, J. Raman Spectroscopy 15,35 (1984).

103. C. A. Melendres and V. A. Maroni., J. Raman Spectroscopy 15, 319 (1984).

104. C. Shannon and A. Campion. J. Phys. Chem. 92, 1385 (1988). 